\title{
Technical and Economic Feasibility Analysis of the No-Fuel Compressed Air Energy Storage Concept
}

May 1976

Prepared for the Energy Research and Development Administration under Contract E(45-1):1830 


\section{NOTICE}

This report was prepared as an account of work sponsored by the United States Government. Neither the United States nor the Energy Research and Development Administration, nor any of their employees, nor any of their contractors, subcontractors, or their employees, makes any warranty, express or implied, or assumes any legal liability or responsibility for the accuracy, completeness or usefulness of any imformation, apparatus, product or process disclosed, or represents that its use would not infringe privately owned rights.

PACIFIC NORTHWEST LABORATORY

operated by

BATTELLE

for the

ENERGY RESEARCH AND DEVELOPMENT ADMINISTRATION

Under Contract E(45-1)-1830

Printed in the Lnited States of America

$$
\text { Avallable from }
$$

National Tectrnical information Service

U.S. Department or Commerce

5285 Port Royal Road

Springfield, Virginia 2215

Price: Printed Copy \$5.50; Microfiche $\$ 2.25$ 


\section{3}

TECHNICAL AND ECONOMIC FEASIBILITY

ANALYSIS OF THE NO-FUEL COMPRESSED

AIR ENERGY STORAGE CONCEPT

by

D. K. Kreid

May 1976

BATTELLE

Pacific Northwest Laboratories

Richland, Washington 99352 


\section{EXECUTIVE SUMMARY}

The goal of the work reported here was to assess the technical and economic feasibility of the "no-fuel" Compressed Air Energy Storage (CAES) concept for load leveling applications in the electric utility industry. The need for load leveling is becoming acute due to the growth in energy use, the increasing cost of generating facilities and the increasing dependence on nuclear power. The growing dependence on gas and oil-fired turbine generators for peaking duty is al so of great concern because of the increasing cost and dwindling supply of suitable fuels. Consequently, the no-fuel CAES concept is doubly attractive for utility applications because it is potentially capable of providing load leveling while reducing the need for turbine fuel.

A detailed thermodynamic and economic analysis of the no-fuel CAES concept has been performed to assess the potential viability of this technique for utility peaking applications. The primary conclusions of the analysis may be stated as follows:

- The no-fuel CAES cycle is potentially capable of a level of performance comparable to that achieved by pumped hydro facilities.

- No insurmountable technical problems have been identified which would rule out its implementation.

- The no-fuel CAES concept does not appear to be economically competitive with conventional CAES systems for conditions foreseeable at this time.

The economic competitiveness of the CAES concept depends on a balance between fuel costs and capital costs. Fuel cost savings achieved by substitution of electrical energy for turbine fuel in the compressors is balanced against additional capital costs for the storage facilities. In the no-fuel CAES concept, the turbine fuel is completely eliminated but increased capital costs far outweigh potential savings in fuel. Therefore, 
al though the no-fuel concept appears technically feasible, it is unlikely to find commercial acceptance.

There are a number of secondary conclusions which arise from the study which deserve mention. Concerning the suitability of available reservoirs for heat storage, we conclude as follows.

- The aquifer appears to be the only storage reservoir which could be used with direct hot air injection.

- Mined caverns (in rock or salt) or aquifers would be suitable for low temperature air storage in conjunction with a regenerative heat storage device.

Finally, two conclusions may be drawn from the economic analysis which potentially have a direct bearing on the design and operation of conventional systems.

- Storage of the heat of compression in an aquifer reservoir does not appear economically advantageous.

- Sent-out power costs are virtually independent of the turbine inlet temperature. This means that it might be economically advantageous to operate CAES systems at a lower heat rate than has been suggested in previous studies. 


\section{CONTENTS}

EXECUTIVE SUMMARY .......................... . .

LIST OF FIGURES . . . . . . . . . . . . . . . vii

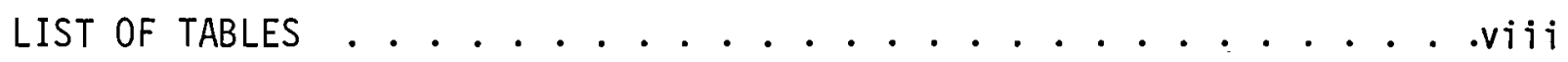

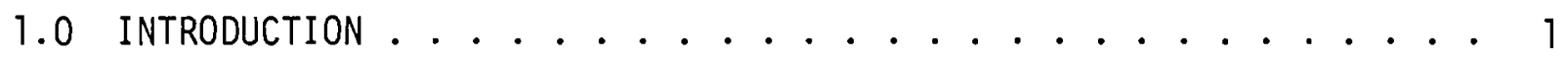

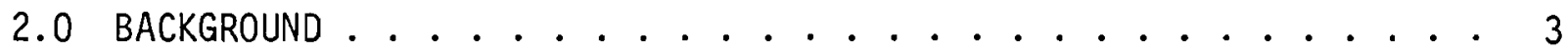

2.1 THE CONVENTIONAL CAES CONCEPT ............. 3

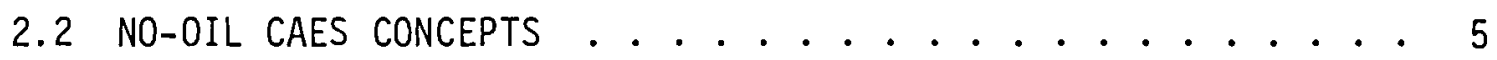

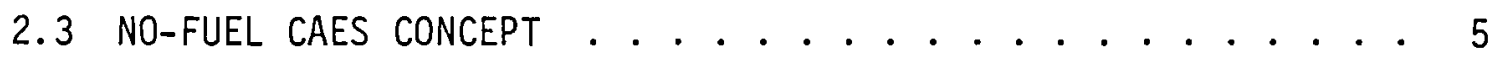

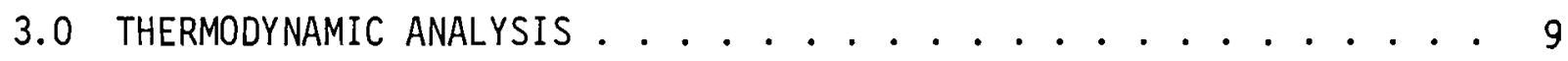

3.1 THE ADIABATIC, NO-FUEL CAES CYCLE . . . . . . . . . 9

3.2 THE NONADIABATIC, NO-FUEL CAES CYCLE . . . . . . . 17

3.3 THE HYBRID CAES CONCEPT . . . . . . . . . . . . . . 20

4.0 ECONOMIC ANALYSIS . . . . . . . . . . . . . . 25

4.1 COST ANALYSIS RATIONALE . . . . . . . . . . . . 25

4.2 CAPITAL COST EQUATIONS . . . . . . . . . . . . 26

4.3 ECONOMIC ANALYSIS RESULTS . . . . . . . . . . . 31

5.0 CONCLUSIONS AND RECOMMENDATIONS ............. 41

5.1 CONCLUSIONS . . . . . . . . . . . . . . . . . . . 41

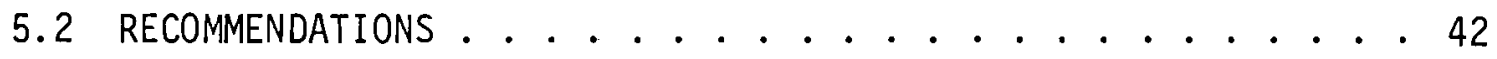

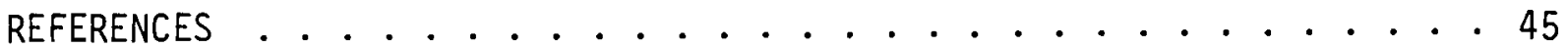

APPENDIX A - ROTATING MACHINERY COSTS . . . . . . . . . A-I

APPENDIX B - STORAGE SYSTEM COSTS . . . . . . . . . . . . . B-1

APPENDIX C - NOMENCLATURE . . . . . . . . . . . . C-1 


\section{FIGURES}

1 Fuel-Fired CAES System Flow Diagram and Thermodynamic Cycle..................... . . 4 4

2 No-Fue 1 CAES System Flow Diagram and Thermodynamic Cycle..................... . 6

3 Nonadiabatic "Hybrid" CAES System Flow Diagram and Thermodynamic Cycle . . . . . . . . . . . . 7

4 Compressor Outlet Temperature for an Adiabatic Compression Process ..................... 14

5 Turbine and Compressor Specific Mass Flow in an Adiabatic, No-Fuel CAES System ................. 15

6 Storage Efficiency for an Adiabatic, No-Fuel CAES System . . . 16

7 Storage Efficiency of a Nonadiabatic No-Fuel CAES Cycle

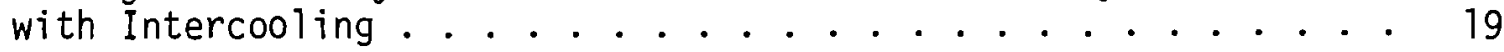

8 Turbine Heat Rate and Overall Heat Rate for a Simple "Hybrid" CAES System . . . . . . . . . . . . . . 24

9 Hybrid CAES System Power Costs: Storage Temperature Effects ...................... 32

10 Hybrid CAES System Power Costs Distribution ......... 33

11 Hybrid CAES System Capital Costs Distribution . . . . . . 34

12 Hybrid CAES System Storage Costs Distribution ......... 35

13 Effect of Well Deliverability (or Aquifer Permeability) on Power Costs................... 36

14 Effects of Relative Costs for Turbine Fuel and Nuclear Fuel for $100^{\circ} \mathrm{F}$ Storage .............. . . 37

15 Effects of Relative Costs for Turbine Fuel and Nuclear Fuel for $700^{\circ} \mathrm{F}$ Storage ............. 38

16 Effect of Duty Cycle on Power Costs ............ 39 


\section{TABLES}

1 Performance Parameters Utilized in the Analysis of the No-Fuel and Hybrid CAES Cycles ............ 13

2 Design Data Utilized to Analyze the Hybrid CAES Cycle ................... . . . 23

3 Cost Equations Utilized to Analyze the Hybrid CAES Cycle.................... 28

4 Financial Data Used in Analysis of the CAES Systems . . . . 29 


\section{TECHNICAL AND ECONOMIC FEASIBILITY ANALYSIS OF THE NO-FUEL COMPRESSED AIR ENERGY STORAGE CONCEPT}

\subsection{INTRODUCTION}

This report will discuss an analysis of the feasibility of the "no-oil" Compressed Air Energy Storage (CAES) concept. The work was performed at Battelle, Pacific Northwest Laboratories under the sponsorship of the Energy Research and Development Administration. The purpose of this document is to convey the final results, conclusions and recommendations to the sponsor and the public at large.

Historically, the electric utility industry has attempted to expand in phase with the growth in energy use while supplying power at the lowest possible cost. This evolutionary process has led to the development of very large and sophisticated nuclear and fossil-fired steam generating facilities, which, for technical and economic reasons, must be operated as nearly as possible to steady-state, peak capacity conditions. To meet the daily and seasonal fluctuations in demand, the industry has become increasingly dependent on gas turbine powered "peaking" generators. In spite of the higher fuel costs, gas turbines have, until recently, provided the best available source of peaking power and, in some areas, have even become responsible for a significant portion of the mid-range and base load capacity.

Exponential growth in worldwide energy use, accentuated and dramatized by the recent Middle East oil embargo, has resulted in chaotic changes in the pricing structure for energy and related products. Consequentiy, prime turbine fuels such as natural gas and oil have become very expensive and their supply is becoming increasingly uncertain. These factors, coupled with the growing nuclear base, are forcing utilities to seek ways for better utilizing their base-loaded facilities and more economical means for providing peaking. As a result, energy storage is an increasingly important element in the planning of the utility industry. 
If suitable facilities were available for short term storage, excess generation capacity, currently idle at night and on weekends, could be used to "charge up" the storage plant. The excess demand during the working day could then be supplemented by regenerating energy from storage. The potential beneficial effects of storage are twofold:

- dependence on prime turbine fuels for peaking is reduced

- base plant facilities are more efficiently utilized.

As a consequence of the considerations outlined above, numerous largescale energy storage concepts suitable for utility use have been suggested and are currently receiving serious consideration. Promising candidates include thermal storage in various media, flywhee 15 , electrolysis, batteries, pumped hydro and compressed air energy storage (CAES). Of these, only pumped hydro is currently in use on a large scale although CAES is undergoing rapid development. 


\subsection{BACKGROUND}

Underground reservoirs for storing compressed air utilized for pneumatic equipment operation have been employed for many years by the mining industry. In addition, underground reservoirs have been routinely employed for at least twenty years to store natural gas and other petroleum derivatives. As early as the late 1940s, various investigators began studying the concept of underground compressed air storage for load leveling applications in the utility industry. Recent years have witnessed a very serious developmental effort in CAES technology evidenced by the construction of the world's first demonstration facility now underway in Germany $(1)$ and the apparent intention of the Energy Research and Development Administration (ERDA) and the Electric Power Research Institute (EPRI) to sponsor development of one or more demonstration facilities in the U. S.

\subsection{THE CONVENTIONAL CAES CONCEPT}

A number of recent review articles and technological assessments $(2-4)$ describe various aspects of CAES in detail. The principles upon which CAES is based are summarized by the pressure-volume and the flow diagrams in Figure 1. Corresponding state points are indicated on both diagrams to aid in tracing the various processes. During the storage phase, the turbine is uncoupled and the motor-generator set is operated as a motor to drive the compressor pumping air into an underground reservoir. The compressor thus provides a convenient means for load dumping, while simultaneously charging up the reservoir.

The reservoir must be sufficiently large to contain the required air mass with minimum leaks and environmental impact. Of several reservoir alternatives, the principle candidates are aquifers and mined caverns in rock and in salt. If necessary, pressure compensation may be added by hydraulic coupling to a surface reservoir. ${ }^{(2-4)}$

During the generation phase, compressed air withdrawn from storage operates the gas turbine connected to the generator set, generating electric power. Since the compressor normally requires almost two-thirds of the 


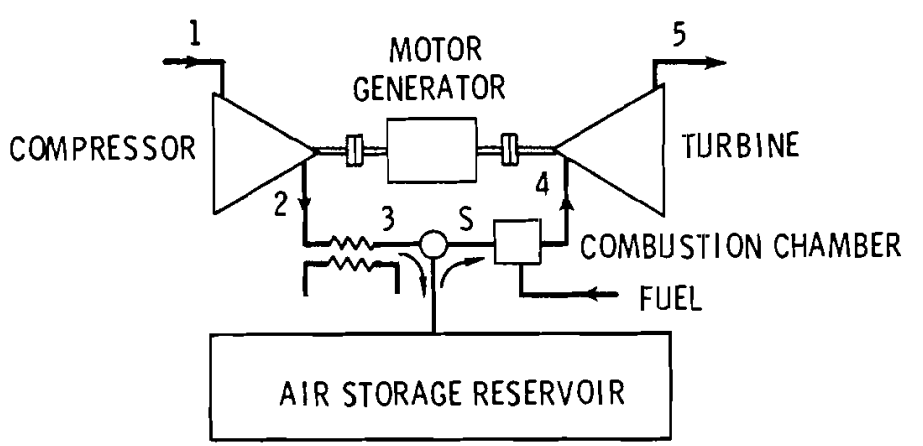

(la)

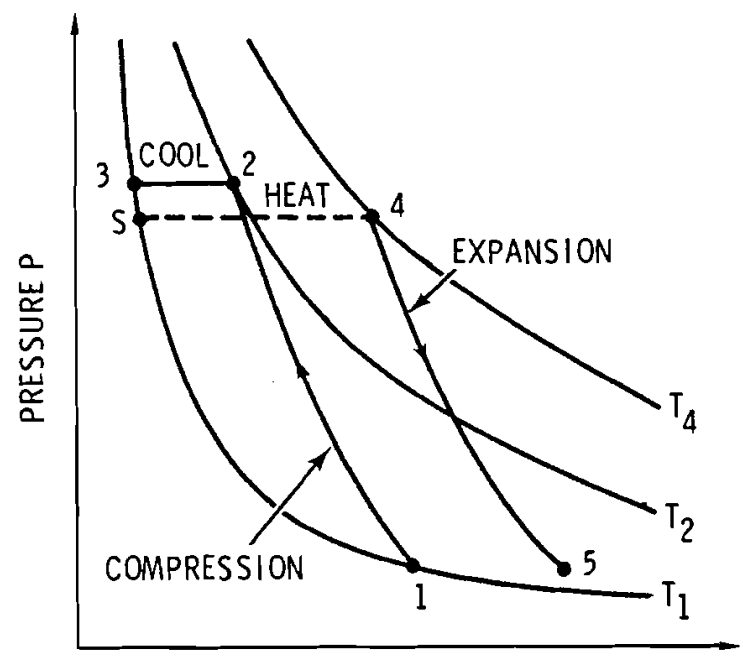

SPECIFIC VOLUME V

(lb)

\section{FIGURE 1. Fuel-Fired CAES System Flow}

Diagram and Thermodynamic Cycle

turbine output, the electrical energy produced by a turbine of a given size at a given fuel consumption rate may be more than doubled. For example, a turbine facility nominally designed for $50 \mathrm{MW}$ output at a heat rate of $11,000 \mathrm{Btu} / \mathrm{kWh}$ can produce about $110 \mathrm{MW}$ at $5000 \mathrm{Btu} / \mathrm{kWh}$ in the CAES system. Although the overall efficiency of the conversion process is reduced, the savings in turbine fuel can be sufficient to offset additional costs for the storage facility and compressor power.

For discussion purposes, the CAES system in Figure 1 is termed "conventional", which implies storage at ambient termperature with turbines fired to temperatures representative of the present technological limit. The 
primary limitations of the conventional CAES concept are the continued, albeit reduced, dependence on turbine fuel and inefficiency due to energy losses in the compressor coolers. The fuel problem is of particular concern because recent developments in the petroleum industry raise serious questions concerning how long oil and natural gas will be available for power generation applications. Therefore, it seems advisable to assess the potential suitability of alternate fuels for CAES and/or the possibility of eliminating the need for turbine fuel al together.

\subsection{NO-OIL CAES CONCEPTS}

In light of the above, two concepts may be included under the title "no-0il" CAES. These are:

- "no-fuel" systems, in which the heat of compression is the sole source of energy for the turbine

- "alternate-fuel" systems employing conventional CAES systems but unconventional fuels.

Much of the technology needed for generating liquid and gaseous fuel from coal and other resources is currently available or under development. $(5,6)$ The use of such fuels should require no major modifications of the conventional CAES technology described in Section 2.1. Long-range fuel availability should not be a problem in view of enormous known coal reserves in the U.S. The problems in alternate fuel production are by no means trivial, but it would seem that the problems in the no-fuel concept are more fundamental and less well-defined. Consequently, this analysis addresses the no-fuel concept first, leaving the problems involved in alternate fuel development for future study.

\subsection{NO-FUEL CAES CONCEPT}

An adiabatic no-fuel CAES system is represented by Figure 2. This system differs from the conventional CAES system of Figure 1 in two important respects: 
- the compressor coolers are eliminated so that the heat of compression is retained;

- the turbine combustion chamber is eliminated and no fuel is utilized.

As shown in Figure 2, the heat of compression is stored in a regenerator, separate from the ambient air reservoir. ${ }^{(7,8)}$ In some cases it may be possible to store the hot air directly in a single reservoir, thereby eliminating the regenerator. The state points in Figure $2 b$ correspond to those indicated in Figure 2a, making it easy to trace the theoretical thermodynamic cycle. For simplicity, all processes are assumed reversible in the diagram.

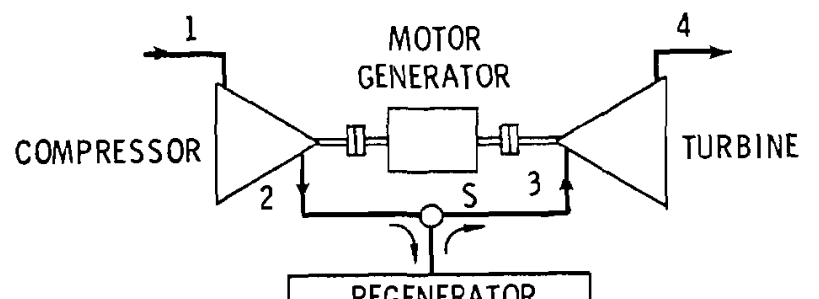

REGENERATOR

AIR STORAGE RESERVOIR

(2a)

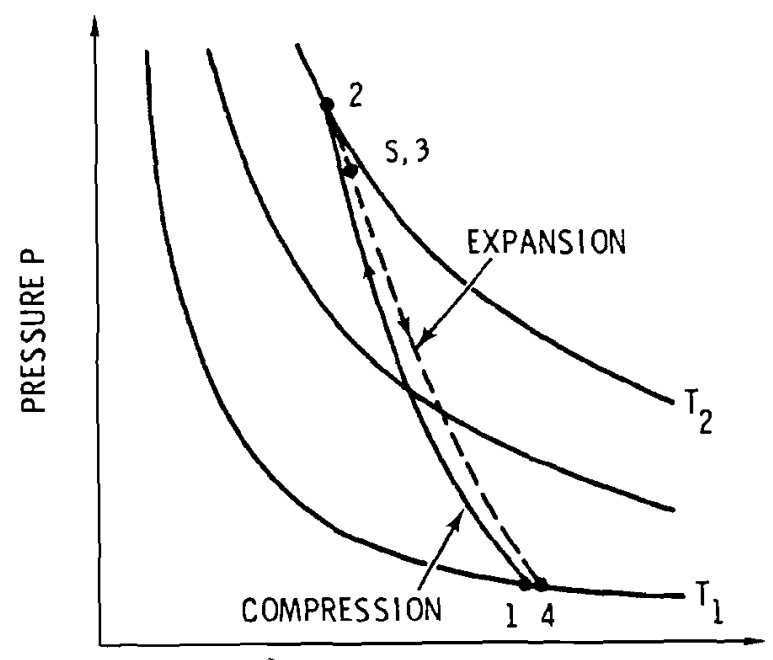

SPECIFIC VOLUME V

(2b)

FIGURE 2. No-Fue1 CAES System Flow Diagram and Thermodynamic Cycle 
The peak temperature tolerable by the regenerator and/or reservoir will determine a limiting compression ratio above which intercooling would have to be provided. Thus, if high pressure operation is desired, a partially cooled CAES system such as that illustrated in Figure 3a might be utilized. However, to compensate for heat loss in the intercooler, the air flowing from the reservoir must be heated or throttled to assure proper turbine inlet conditions with a net loss in system efficiency and output. Alternatively, two-stage storage with reheat might be employed where all compression energy could be stored and subsequently reclaimed to regenerate power. The latter is currently being studied $(7,8)$ and will receive no additional attention in this investigation.
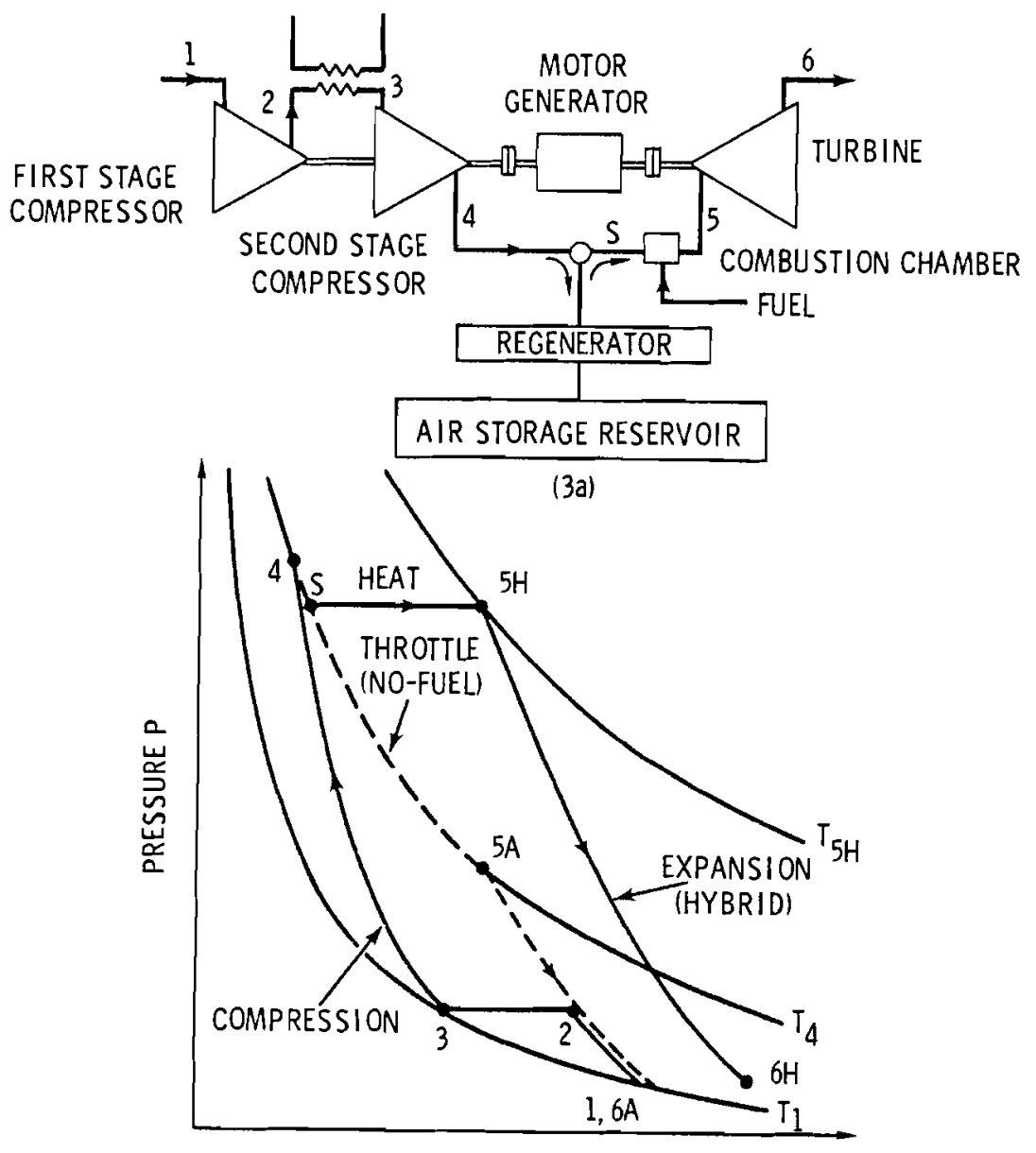

SPECIFIC VOLUME $V$

(3b)

FIGURE 3. Nonadiabatic "Hybrid" CAES System

Flow Diagram and Thermodynamic Cycle 


\subsection{THERMODYNAMIC ANALYSIS}

\subsection{THE ADIABATIC, NO-FUEL CAES CYCLE}

For analysis purposes, the simple Brayton cycle model of Figure 2 will be employed. Ideal gas behavior is assumed and all transport properties are assumed constant. Compressor and turbine performances will be characterized by the standard isentropic efficiencies

$$
\begin{aligned}
n_{c} & =\frac{i \text { sentropic compression work }}{\text { actual compressor work }} \\
& =\frac{h_{2}^{\prime}-h_{1}}{h_{2}-h_{1}} \\
& =\frac{T_{2}^{\prime}-T_{1}}{T_{2}-T_{1}}
\end{aligned}
$$

and

$$
\begin{aligned}
\eta_{t} & =\frac{\text { actual turbine work }}{\text { isentropic turbine work }} \\
& =\frac{h_{4}-h_{5}}{h_{4}-h_{5}} \\
& =\frac{T_{4}-T_{5}}{T_{4}-T_{5}}
\end{aligned}
$$

where state points are defined in Figure 2. States $2^{\prime}$ and $5^{\prime}$ are the theoretical states reached by isentropic processes from the actual initial state to the actual final pressure. The motor-generator set efficiency must, in general, be defined differently for each operational function:

$$
\begin{aligned}
\eta_{m} & =\frac{\text { motor shaft output }}{\text { electrical input }} \\
& =\frac{\left(w_{\text {out }}\right)_{m}}{\left(w_{\text {in }}\right)_{m}}
\end{aligned}
$$

and

$$
\begin{aligned}
\eta_{g} & =\frac{\text { generator electrical output }}{\text { shaft input }} \\
& =\frac{\left(w_{\text {out }}\right)_{g}}{\left(w_{\text {in }}\right)_{g}} .
\end{aligned}
$$


The performance of the reservoir and associated piping will be specified by a pressure recovery factor,

$$
\begin{aligned}
\delta_{p} & =\frac{\text { turbine inlet pressure }}{\text { compressor outlet pressure }} \\
& =\frac{P_{4}}{P_{2}} ;
\end{aligned}
$$

by a temperature recovery factor,

$$
\begin{aligned}
\delta_{T} & =\frac{\text { temperature differential at turbine inlet }}{\text { temperature differential at compressor outlet }} \\
& =\frac{T_{4}-T_{0}}{T_{2}-T_{0}} ;
\end{aligned}
$$

and by a mass recovery factor,

$$
\begin{aligned}
\delta_{\mathrm{m}} & =\frac{\text { mass expanded in turbine }}{\text { mass injected by compressor }} \\
& =\frac{\Delta \mathrm{m}_{\text {turb }}}{\Delta \mathrm{m}_{\text {comp }}}
\end{aligned}
$$

In equation (6), $T_{0}$ is the ambient temperature so that $\delta_{T}$, in effect, measures how well the available energy (relative to the environment) is retained in storage.

Finally, to characterize the performance of the CAES facility as a whole, an "energy storage efficiency", $\eta_{S}$, is defined as

$$
\begin{aligned}
n_{s} & =\frac{\text { electrical energy generated from storage }}{\text { electrical energy input to the compressor motor }} \\
& =\frac{\Delta m_{t} n_{g} n_{t}\left(h_{4}-n_{5}{ }^{\prime}\right)}{\Delta m_{c}\left(n_{2}^{\prime}-n_{1}\right) /\left(n_{m} n_{c}\right)} \\
& =n_{g} n_{m}{ }^{n} c^{n_{t}} \delta_{m}\left(\frac{T_{4}-T_{5}{ }^{\prime}}{T_{2}{ }^{\prime}-T_{1}}\right)
\end{aligned}
$$

In the analysis, all component performance parameters are assumed constant when, in practice, significant variability can be expected during a typical daily cycle. In particular, the reservoir charge and discharge pressures and temperatures will vary considerably during each cycle, as will 
$\delta_{p}$ and $\delta_{T}$. All values employed must therefore be considered as averages representing typical operating conditions.

It should also be noted that the storage efficiency as defined here is completely adequate to characterize no-fuel CAES systems, but would be inadequate for conventional CAES systems since the effects of fuel addition would not be properly accounted for. At this time, there is no generally approved definition for a "storage efficiency" for conventional CAES systems although several definitions have been suggested. (1-4)

In the charging phase of the cycle, the compressor operates at a nominal compression ratio, $r_{c}=P_{2} / P_{1}$, which must be sufficient to overcome the back-pressure at the reservoir inlet. For an aquifer or an uncompensated mined cavity, the pressure will rise as the reservoir is charged, which requires the compressor to adjust to a variable back-pressure. Alternatively, the compressor could be sized for the maximum cycle pressure and the outlet throttled to achieve a constant compression ratio as the reservoir fills. For the analysis, $r_{c}$ will be treated as a constant and any throttling required will be absorbed into the pressure recovery factor $\delta_{p}$.

Assuming an isentropic process, the end states of the compression process are related by

$$
\frac{T_{2}^{\prime}}{T_{1}}=\left(\frac{P_{2}}{P_{1}}\right)^{\frac{\gamma-1}{\gamma}}=r_{c}^{n}
$$

where, for an ideal diatomic gas, $\gamma=1.4$ and $\eta=\gamma-1 / \gamma=0.286$.

During the power generation phase, the delivery pressure at the well head will also decrease as the reservoir discharges (unless hydraulic compensation is employed). To operate the turbine at a constant expansion ratio, it may thus be desirable to design the turbine for the minimum delivery pressure and throttle the inlet when necessary. Again, the turbine expansion ratio $r_{t}=P_{5} / P_{4}$ is treated as a constant and throttling losses are absorbed into $\delta_{p}$ as they were for the compressor.

The end states for an isentropic expansion process are related by 


$$
\frac{T_{4}}{T_{5}^{\prime}}=\left(\frac{P_{4}}{P_{5}}\right)^{\frac{\gamma-1}{\gamma}}=r_{t}^{n} \text {. }
$$

From equation (5),

$$
\delta_{p}=\frac{P_{4} / P_{5}}{P_{2} / P_{1}}\left(\frac{P_{1}}{P_{5}}\right)=\frac{r_{t}}{r_{c}}
$$

where the inlet and outlet pressures $P_{1}$ and $P_{5}$ are assumed ambient.

From equations (8), (9), and (10), the storage efficiency may be written as

$$
n_{s}=n_{g} n_{m}^{n} c^{n} t^{\delta}\left(\frac{T_{4}}{T_{1}}\right)\left(\frac{1-r_{t}^{-n}}{r_{c}^{n}-1}\right)
$$

and then, from equations $(5),(6)$, and (7),

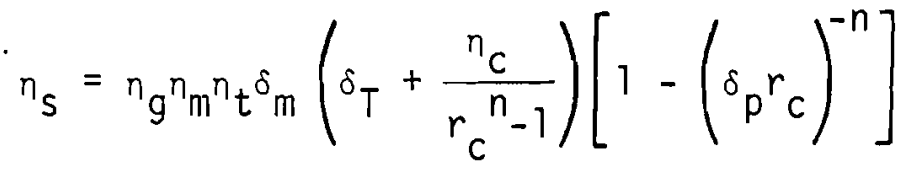

Finally, the overall thermodynamic efficiency for power generated from storage is the product of the base plant efficiency $n_{b}$ and the storage efficiency $\eta_{\mathrm{s}}$

$$
n_{t h}=n_{s} n_{b}
$$

Ten different efficiencies and recovery parameters required to specify the performance of various components and systems related to the "simple" no-fuel CAES cycle are defined. For reference, these are summarized in Table 1 along with the numerical values employed. For the analysis, it is assumed that the reservoir and pipes do not leak, so that $\delta_{m}=1$. A detailed thermal hydraulic analysis of the reservoir response is beyond the scope of this work; thus, $\delta_{p}$ and $\delta_{T}$ were treated as independent variables for a range of "expected" values. 
TABLE 1. Performance Parameters Utilized in the Analysis of the No-Fuel and Hybrid CAES Cycles

\begin{tabular}{|c|c|c|c|c|}
\hline $\begin{array}{l}\text { System or } \\
\text { Component }\end{array}$ & $\begin{array}{l}\text { Performance } \\
\text { Parameter }\end{array}$ & Symbol & $\begin{array}{l}\text { Value }(\mathrm{s}) \\
\text { Employed }\end{array}$ & $\begin{array}{l}\text { Equation } \\
\text { Number }\end{array}$ \\
\hline compressor & $\begin{array}{l}\text { isentropic } \\
\text { efficiency }\end{array}$ & $n_{c}$ & 0.9 & (1) \\
\hline turbine & $\begin{array}{l}\text { isentropic } \\
\text { efficiency }\end{array}$ & $\eta_{t}$ & 0.9 & (2) \\
\hline motor & efficiency & $n_{m}$ & 0.95 & (3) \\
\hline generator & efficiency & $n_{g}$ & 0.95 & (4) \\
\hline reservoir & $\begin{array}{l}\text { pressure } \\
\text { recovery factor }\end{array}$ & $\delta_{p}$ & $0.6-1.0$ & (5) \\
\hline reservoir & $\begin{array}{l}\text { temperature } \\
\text { recovery factor }\end{array}$ & $\delta_{t}$ & $0.6-1.0$ & (6) \\
\hline reservoir & $\begin{array}{l}\text { mass recovery } \\
\text { factor }\end{array}$ & $\delta_{m}$ & 1.0 & (7) \\
\hline $\begin{array}{l}\text { CAES } \\
\text { facility }\end{array}$ & $\begin{array}{l}\text { storage } \\
\text { efficiency }\end{array}$ & $n_{s}$ & & (8) \\
\hline $\begin{array}{l}\text { base plant } \\
\text { facility }\end{array}$ & $\begin{array}{l}\text { conversion } \\
\text { efficiency }\end{array}$ & $n_{b}$ & 0.38 & \\
\hline $\begin{array}{l}\text { total } \\
\text { system }\end{array}$ & $\begin{array}{l}\text { conversion } \\
\text { efficiency }\end{array}$ & $n_{\text {th }}$ & & (14) \\
\hline
\end{tabular}

Reviewing equation (13) for $n_{s}$, three conclusions can immediately be drawn:

- $n_{s}$ is an increasing function of $r_{c}$.

- The dependence of $n_{s}$ on $n_{c}$, $\delta_{p}$ and $r_{c}$ diminishes with increasing $r_{c}$.

- The maximum possible storage efficiency is given approximately by

$$
\left(n_{s}\right)_{\max } \leq n_{g} n_{m} n_{t} \delta_{m} \delta_{T} .
$$

If, for example, $n_{g}=n_{m}=0.95, n_{t}=n_{c}=\delta_{T}=0.9, \delta_{m}=1$ and $n_{b}=0.38$, the maximum storage efficiency is 73 percent and the maximum thermodynamic efficiency is 28 percent. However, to achieve and maintain 
this level of performance, the storage facility and turbomachinery would have to be very carefully designed and fabricated and a very sophisticated system for monitoring and control would be required.

Figures 4, 5, and 6 illustrate the effects of various design parameters on system performance. Figure 4 shows the compressor outlet temperature for adiabatic compression with an inlet condition of $60^{\circ} \mathrm{F}$ and a compressor efficiency of 90 percent. The maximum allowable pressure ratio for adiabatic compression may be determined from Figure 4 if the temperature limit of the reservoir system can first be specified.

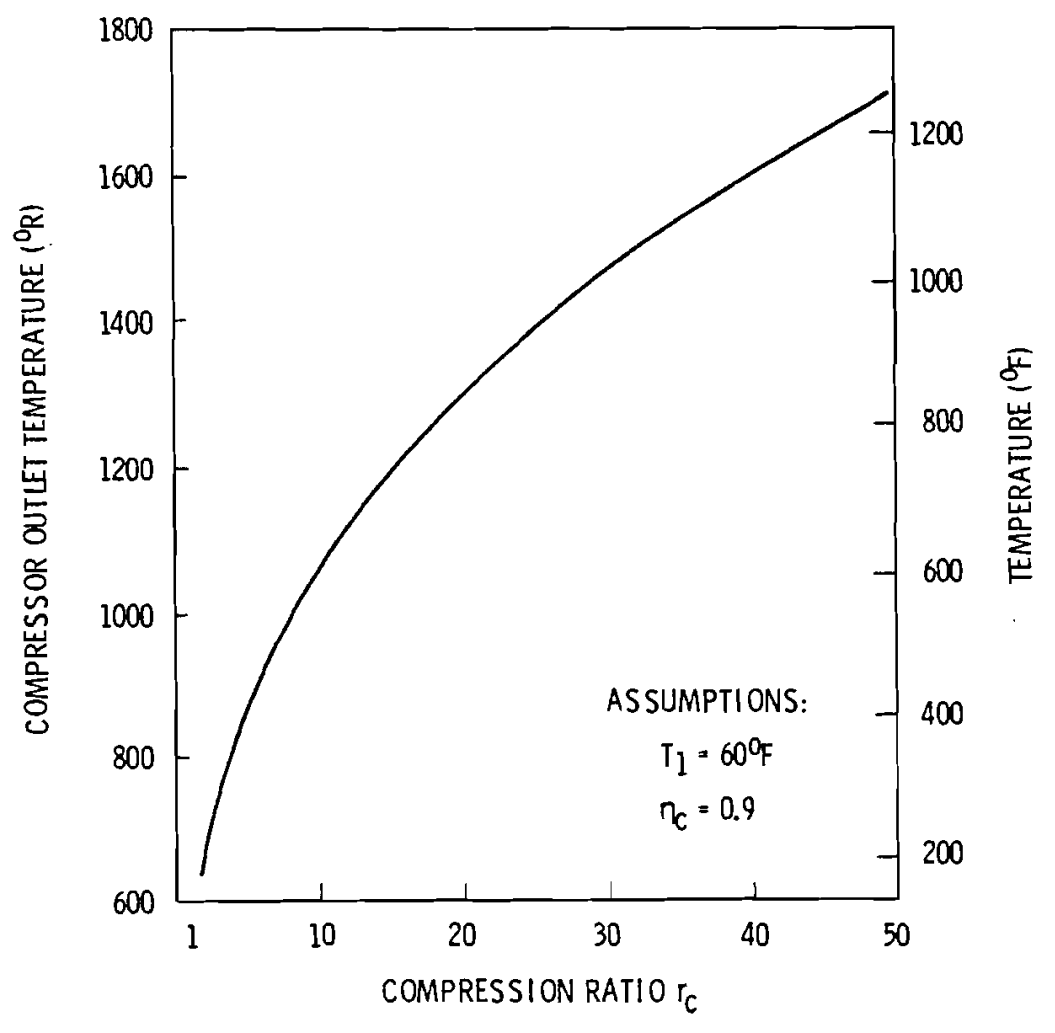

FIGURE 4. Compressor Outlet Temperature for an Adiabatic Compression Process 
Figure 5 illustrates the specific mass flow in $1 \mathrm{~b}_{\mathrm{m}} / \mathrm{kWh}$ and its reciprocal, the specific work for the compressor and the turbine. The compressor line gives the amount of mass transferred to storage for a given electrical energy input and the turbine line gives the total mass displaced by the turbine for a given energy output. Given the compressor power and run time and the peaking power required, Figure 5 may then be used to determine how long the peaking plant may be operated. In practice, the relative sizing of the compressor and turbine will depend on the utility needs, the magnitude and duration of demand peaks and valleys, and the mix of generating facilities in place. There are, however, certain considerations which cause design features and problems peculiar to the no-fuel CAES concepts. For example, in the conventional CAES system, it is practical to size the compressor so that the turbine-compressor system can be run as a unit in emergencies. This, of course, is not possible with a no-fuel sys tem.

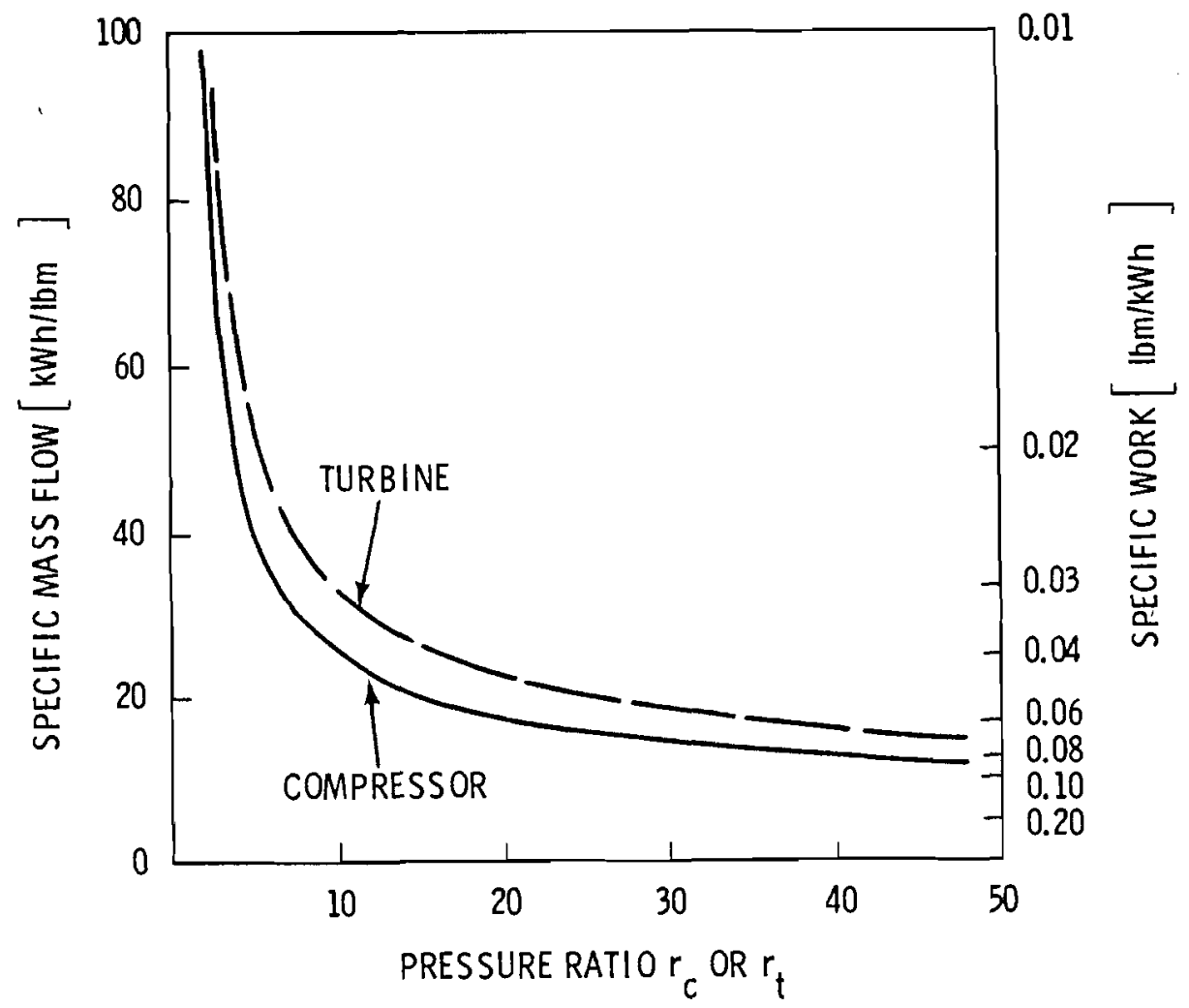

FIGURE 5. Turbine and Compressor Specific Mass Flow in an Adiabatic, No-Fuel CAES System 
Figure 6 illustrates the effects of heat and pressure loss on the system performance. For the calculations, the motor-generator efficiencies are assumed to be 95 percent and compressor and turbine efficiencies are assumed to be 90 percent; both approximate current state-of-the-art. ${ }^{(9)}$ As can be seen from Figure 6 , the rate of increase of $\eta_{s}$ with $r_{c}$ is slight for compression ratios greater than about 10-15. There is, therefore, little incentive to design for higher pressures unless other considerations require it. At low pressures, $n_{s}$ falls off very steeply with $r_{c}$, so very low pressure operation is certainly to be avoided.

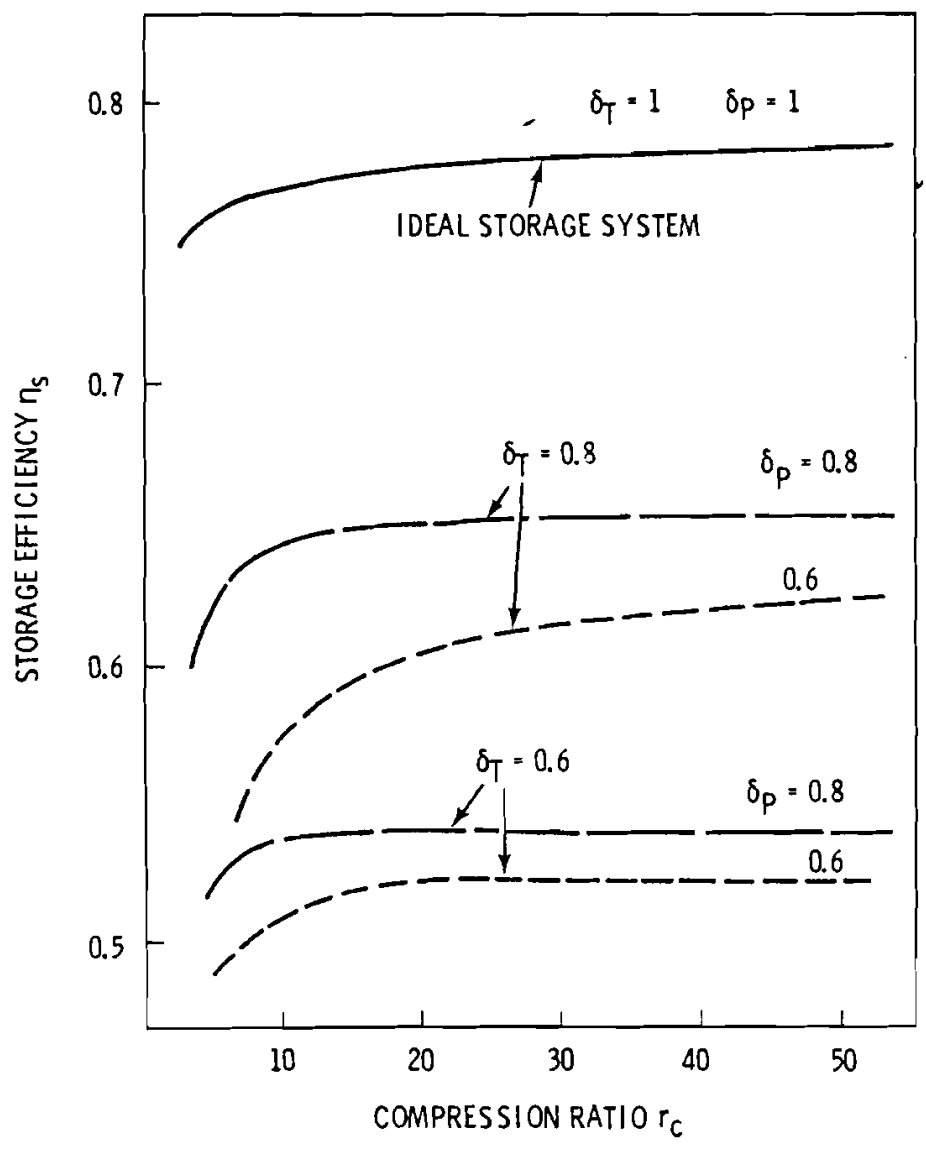

FIGURE 6. Storage Efficiency for an Adiabatic, No-fuel CAES System 
Heat losses in storage result in lower temperatures at the turbine inlet $\left(\delta_{T}<1\right)$ which, in turn, cause an approximately proportional reduction in the efficiency, $n_{s}$. In addition, the lower temperature at the turbine inlet can, in some cases, result in a sub-ambient exhaust temperature if the total available expansion ratio is utilized. This can lead to the formation of ice in the low pressure stages of the turbine, a condition not normally tolerated in gas turbines. Consequently, the inlet flow must be "conditioned" in this case by heating or throttling to assure above-ambient temperature at the outlet. This further complicates the design and detracts from the system performance. It is therefore doubly important to minimize heat losses in a no-fuel CAES system.

Figure 6 shows the pressure losses in the system $\left(\delta_{p}<1\right)$ to have a much less deleterious effect on the efficiency than heat losses. In fact, if heat losses are severe, additional throttling may even be required, as discussed above. Although unnecessary pressure losses are to be avoided, it is apparent that significant pressure losses could normally be tolerated without greatly affecting the overall system performance.

\subsection{THE NONADIABATIC NO-FUEL CYCLE}

As mentioned briefly in the introduction, in some cases it may prove technically or economically advantageous to design a no-fuel CAES system to utilize very high storage pressures for which adiabatic compression would yield a compressor outlet temperature in excess of the design 1 imit (see Figure 4). For example, aquifer systems must operate at a mean pressure equal to the hydrostatic head at the depth of the permeable bed. Therefore, the pressure dictated by the aquifer at hand must be used. Alternatively, it may be advantageous to design a mined cavern for very high pressures to reduce the amount of material which must be extracted. For either application, some form of compressor cooling must be employed, perhaps by an arrangement such as that illustrated in Figure 3 .

A number of significant conclusions regarding the design of the system in Figure 3 can be deduced from the pressure-volume diagram (3b). Since the object of the compression is to reach state point "4" with the minimum 
work, intercooling rather than aftercooling is required, and the first stage compression ratio should be minimized. These assertions are evident by observing that the compressor work is reduced by any change which moves the compression process line to the left in Figure $3 \mathrm{~b}$. In addition, if the gas is delivered to the turbine at conditions near the state denoted by "4" (no pressure loss in the reservoir), full expansion to atmospheric pressure will result in a sub-ambient outlet temperature, as discussed above. To prevent this from happening, the inlet gas can be heated to state $5 \mathrm{H}$, the inlet throttled to state $5 \mathrm{~T}$ or the outlet throttled. In a no-fuel system, inlet heating would have to be done electrically by direct resistance heating or by off-peak resistance heating of a regenerative device. In either case, the electric energy required would ultimately subtract from the net output of the system. The throttling process would be simpler to accomplish, but variation of the inlet conditions would require variable throttling, making maintenance of constant turbine inlet conditions difficult. In practice, it may prove advantageous to use a combination of heating and throttling for inlet control.

Figure 7 illustrates the effect of the intercooler on the storage efficiency, assuming the turbine inlet is throttled to state $5 \mathrm{~A}$ to prevent turbine "icing". For the calculation, the component efficiencies are assumed the same as in Table 1, the inlet and interstage temperatures are $60^{\circ} \mathrm{F}$ and the second stage compression ratio $r_{c 2}$ is 10:1. These values roughly represent what might conceivably be accomplished with currently available equipment of U. S. manufacture without major redesign. For the analysis, the first stage compression ratio is variable, but the second stage compression ratio is held constant. The interstage temperature is constant at $60^{\circ} \mathrm{F}$; hence, the required amount of cooling increases as $r_{c}$ increases, but the second stage outlet temperature $T_{3}$ remains constant at about $600^{\circ} \mathrm{F}$. The data for $r_{c}<10$ (where no intercooling is needed) are not shown in Figure 7 because these data appear in more detail in Figure 6.

The curves of Figure 7 show that the storage efficiency reaches a maximum somewhere near $r_{c}=10$, depending on the values of $\delta_{p}$ and $\delta_{T}$ employed. As the compression ratio $r_{c}$ increases, $n_{s}$ decreases due to the increasing 


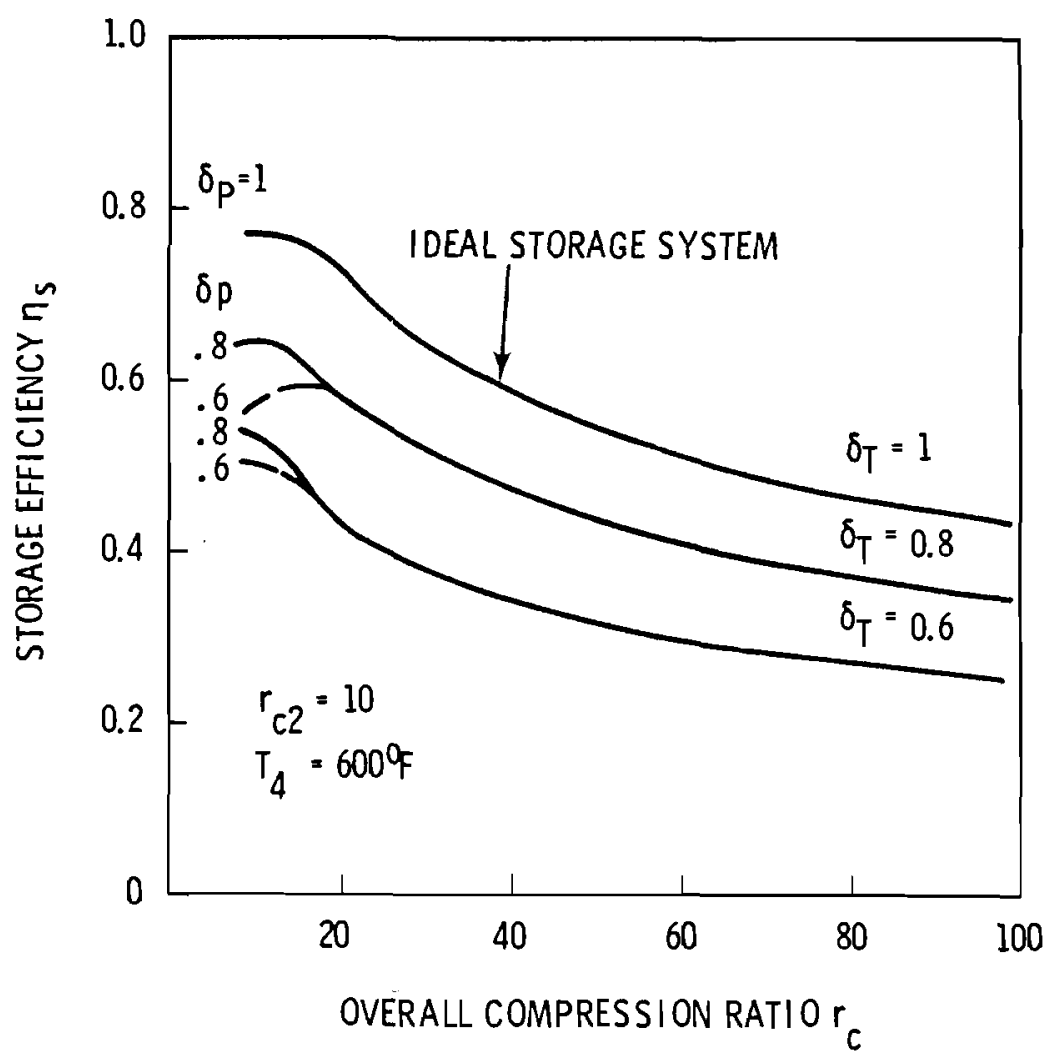

FIGURE 7. Storage Efficiency of a Nonadiabatic No-Fuel CAES Cycle with Intercooling

loss of heat in the intercoolers. For losses in the reservoir, $n_{s}$ is reduced roughly in proportion with the temperature recovery factor $\delta_{T}$, as was found for the adiabatic no-fuel cycle. However, except at low values of $r_{c}$, pressure losses in storage $\left(\delta_{p}<1\right)$ have virtually no effect on $n_{s}$ for the range of values considered. This is so because the calculations are based on a model which assumes that throttling occurs at the turbine inlet to assure an exhaust temperature at or above the ambient. Thus, it makes no difference whether the required pressure drop occurs in the storage system, at an inlet throttling valve or in a combination of the two.

Finally, it seems probable that a no-fuel CAES system intended for high pressure applications is doomed to low storage efficiencies unless some means can be devised for storage and subsequent reuse of the heat 
extracted in the intercoolers. Although the latter possibility is being

investigated, ${ }^{(8)}$ it is questionable whether the economics could ever be sufficient to make such a system attractive for utility storage uses. The best alternative appears to be development of applications employing compression ratios of about 10:1, which require little or no cooling.

\subsection{THE HYBRID CAES CONCEPT}

To proceed with the cost analysis for the no-fuel CAES concept, a "hybrid" system utilizing partially cooled compressors with storage at intermediate temperatures and low temperature turbines fired at intermediate heat rates will be defined. A cost equation for this hybrid system as a function of the storage temperature $T_{s}$ and the firing temperature $T_{f}$ will be established and then extrapolated to obtain an estimate of costs for no-fuel systems. First, the thermodynamic performance of the hybrid system will be analyzed because certain features of this concept are, in their own right, significant to the general concept of CAES technology.

In Section 2.4, $n_{s}$ was shown as a very slowly increasing function of $r_{c}$ for compression ratios greater than about 10 . From discussions with manufacturers, compressor outlet temperatures of about $600^{\circ} \mathrm{F}$ (for an adiabatic compression ratio of about 10) represent the approximate limit of endurance for current rotary compressors with reasonable modifications. By cooling, higher compression ratios can be achieved quite simply, but the heat lost in the process subtracts from the system performance, as illustrated by Figure 7. Interestingly, gas turbines of U. S. manufacture also typically operate at compression and expansion ratios of about 10 to 12 .

The above factors indicate that operation at very high pressures is probably of questionable value for no-fuel CAES systems. Therefore, the present analysis is 1 imited to a fixed pressure ratio representative of current technology for which cost data are available. Efforts are concentrated on the more fundamental aspects of variable heat rate and storage temperature. If further developments indicate that significant gains might be achieved by going to higher pressures, that subject can also be dealt with by an extension of the present analysis. 
The hybrid CAES system may be represented by either Figure 1 or Figure 3, depending on whether the cooling is accomplished in an aftercooler, an intercooler or both. For simplicity, the cycle is described in terms of Figure 1, al though a system such as that in Figure 3 would be more efficient. For the discussion, the compressor outlet temperature $\mathrm{T}_{3}$ and the storage temperature $T_{S}$ are variables because of the varying amounts of cooling provided. In addition, the turbine inlet temperature $\mathrm{T}_{4}$ is variable because of the variable turbine heat rate. By definition, the turbine heat rate is given by

$$
\begin{aligned}
Q_{t} & =\frac{\text { heat energy in as fuel }}{\text { shaft work output }} \\
& =\frac{\left(h_{4}-h_{5}\right) / n_{h}}{n_{g}\left(h_{4}-h_{5}\right)}
\end{aligned}
$$

where $n_{h}$ is the efficiency of the combustor, assumed as 1.0. A Coefficient of Performance (COP) is then defined as

$$
\begin{aligned}
\text { COP } & =\frac{\text { turbine work output }}{\text { power input to compressor }} \\
& =\frac{n_{g}\left(h_{4}-h_{5}\right)}{\left(h_{2}-h_{1}\right) / n_{m}} .
\end{aligned}
$$

The COP as defined above has been called a storage efficiency in some reports. However, this is misleading because the input does not explicitly include the heat input in the combustor and, as a consequence, COP can be greater than 1.0. When $Q_{t}$ is zero, COP is the same as the storage efficiency $n_{s}$ for the no-fuel system.

The overall thermodynamic efficiency for power produced from storage may be given by

$$
\begin{aligned}
n_{t h} & =\frac{\text { turbine work output }}{\text { total energy input }} \\
& =\frac{n_{g}\left(h_{4}-h_{5}\right)}{\left(h_{2}-h_{1}\right) / n_{m} n_{b}+\left(h_{4}-h_{s}\right) / n_{h}}
\end{aligned}
$$


where $n_{b}$ is the thermodynamic efficiency of the base plant producing the electricity which drives the compressor. The overall heat rate for power produced from storage is just the inverse of $n_{t h}$, or

$$
Q_{\text {th }}=\frac{3413}{n_{\text {th }}}\left[\frac{\mathrm{Btu}}{\mathrm{kWh}}\right]
$$

The efficiencies of all system components are the same as in Table 1.

The analysis assumes a compression ratio of 18, an expansion ratio of 12 and storage temperature in the range from ambient to $700^{\circ} \mathrm{F}$. From previous analyses of aquifers for CAES applications $(10,11)$, a pressure loss of six atmospheres due to injection and withdrawal is realistic or possibly slightly optimistic, depending on the flow rates assumed. The expansion ratio is representative of current equipment designs ${ }^{(2)}$ and the peak temperature is only slightly higher than estimated current compressor capabilities. Other pertinent design data are listed in Tables 1 and 2.

In Figure 8 , the results for the turbine heat rate $Q_{t}$ and overall system heat rate $Q_{\text {th }}$ are shown as a function of the storage temperature $T_{s}$ and for turbine inlet or firing temperatures $T_{f}$ of $100^{\circ} \mathrm{F}$ and $700^{\circ} \mathrm{F}$. Depending on the inlet temperature, the potential savings in heat rate for $700^{\circ} \mathrm{F}$ storage (as compared to $100^{\circ} \mathrm{F}$ storage) varies from over 3500 [Btu/kWh] at $T_{f}=700^{\circ} \mathrm{F}$ to about $2000[\mathrm{Btu} / \mathrm{kWh}]$ at $T_{f}=100^{\circ} \mathrm{F}$. For the no-fuel system (where $T_{s}=T_{f}=700^{\circ} \mathrm{F}$ ) the overall heat rate is $Q_{t h} \simeq 13,800[\mathrm{Btu} / \mathrm{kWh}]$ corresponding to an overall thermodynamic efficiency of 25 percent.

For storage at $700^{\circ} \mathrm{F}$ and firing at $1950^{\circ} \mathrm{F}$ (conventional CAES with heat storage), $Q_{t} \simeq 4000, Q_{t h} \simeq 10,500$ corresponding to an overall conversion efficiency of 33 percent. It is significant that conventional technology with ambient storage utilizing exhaust gas heat recovery could produce essentialiy the same overall efficiency, al though more turbine fuel would be consumed. Exhaust heat recovery is not possible with CAES systems utilizing hot storage because the gas is hot when it leaves the reservoir. 
TABLE 2. Design Data Used to Analyze the Hybrid CAES Cycle

\begin{tabular}{|c|c|c|c|}
\hline Symbol & Item Description & Value & Reference \\
\hline $\mathrm{T}_{0}$ & ambient temperature & $60^{\circ} \mathrm{F}$ & \\
\hline $\mathrm{T}_{1}$ & compressor inlet temperature & $60^{\circ} \mathrm{F}$ & \\
\hline $\mathrm{T}_{2}$ & compressor outlet temperature & variable & \\
\hline$T_{3}$ & reservoir inlet temperature & variable & \\
\hline$T_{s}$ & reservoir outlet temperature & variable & \\
\hline$T_{4}=T_{f}$ & turbine inlet temperature & variable & \\
\hline$T_{\text {fo }}$ & $\begin{array}{l}\text { firing temperature assumed } \\
\text { for the "conventional" } \\
\text { CAES system }\end{array}$ & $1950^{\circ} \mathrm{F}$ & (2) \\
\hline$T_{\text {so }}$ & $\begin{array}{l}\text { storage temperature assumed for } \\
\text { the "conventional" CAES system }\end{array}$ & $125^{\circ} \mathrm{F}$ & (2) \\
\hline$P_{0}$ & ambient pressure & $1 \mathrm{~atm}$ & \\
\hline$r_{c}$ & compression ratio $=P_{2} / P_{1}$ & 18 & \\
\hline \multirow[t]{2}{*}{$r_{t}$} & $\begin{array}{l}\text { expansion ratio }=P_{4} / P_{5} \\
\text { bubble cushion factor }=\end{array}$ & 12 & \\
\hline & $\frac{\text { cycle volume }}{\text { total volume }}$ & 8 & (2) \\
\hline$\tau$ & daily use & $10 \mathrm{hr}$ & $(2,3)$ \\
\hline$u_{a}$ & annual use & $2000 \mathrm{hr}$ & $(2,3)$ \\
\hline $\begin{array}{l}k_{t} \\
v_{s}\end{array}$ & $\begin{array}{l}\text { turbine run time/comp. run time } \\
\text { aquifer storage capacity }\end{array}$ & $10^{4}\left[\frac{\mathrm{ft}^{3}}{\mathrm{acre}}\right]$ & $(10,11,12)$ \\
\hline Mo & $\begin{array}{l}\text { well flow rate at nominal } \\
\text { design conditions }\end{array}$ & $10^{5}\left[\frac{1 \mathrm{bm} / \mathrm{hr}}{\mathrm{We} 11}\right]$ & $(10,11,12)$ \\
\hline$\rho_{r}$ & density of rock & $140\left[\frac{1 \mathrm{bm}}{\mathrm{ft}^{3}}\right]$ & (14) \\
\hline$\varepsilon_{r}$ & porosity of rock & 0.18 & (13) \\
\hline$C_{p r}$ & specific heat of rock & $0.22\left[\frac{B t u}{1 b_{m}^{\circ} R}\right]$ & (14) \\
\hline
\end{tabular}




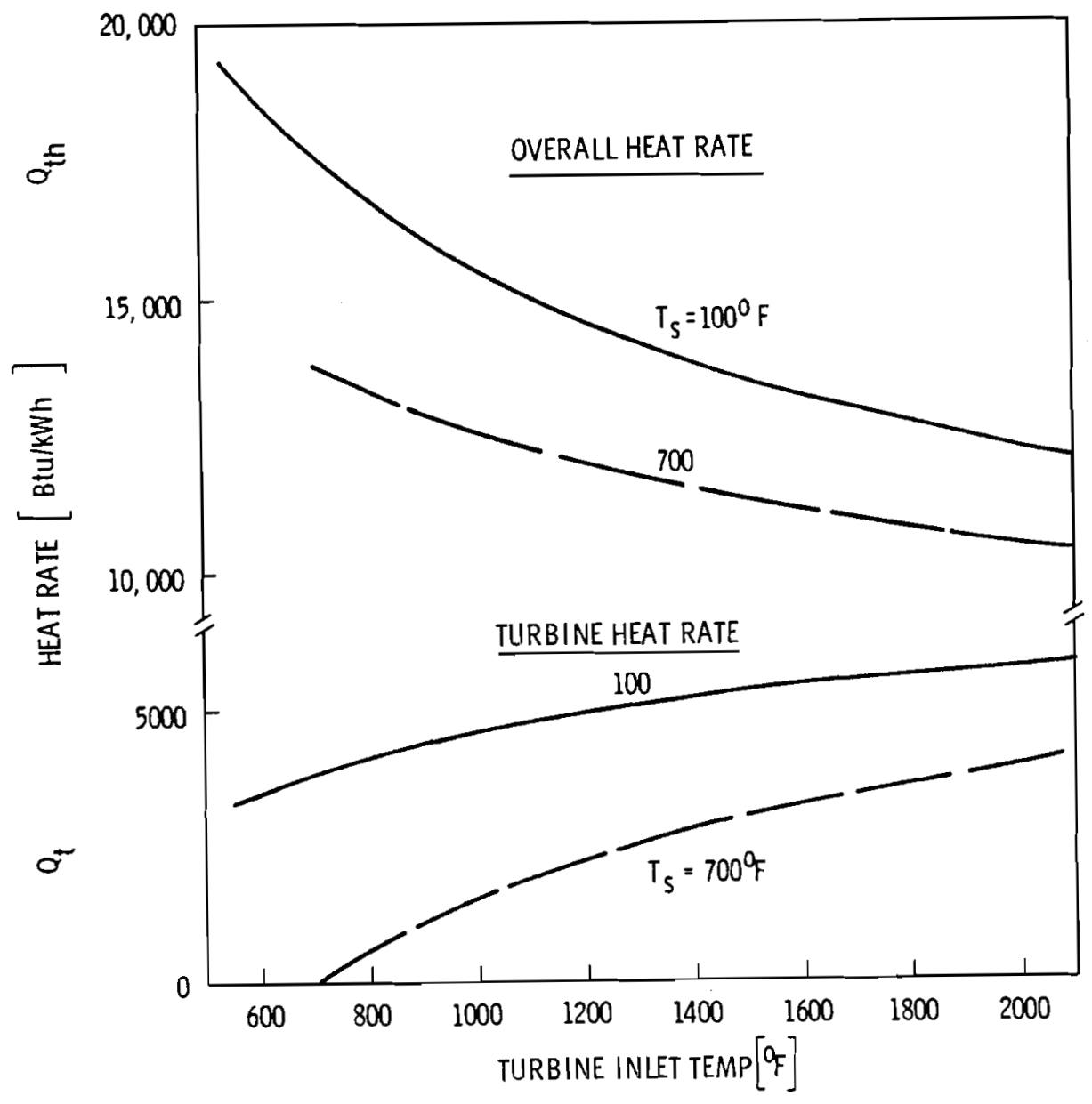

FIGURE 8. Turbine Heat Rate and Overall Heat Rate for a Simple "Hybrid" CAES System 


\subsection{ECONOMIC ANALYSIS}

\subsection{COST ANALYSIS RATIONALE}

Several analyses of the economic feasibility of "conventional" CAES systems are available ${ }^{(2-4)}$. A representative sampling of the results of these investigations reveals significant differences of opinion regarding the costs of various system components and the resultant power costs, despite the fact that these "conventional" systems are based on technology essentially available today with only minor modifications. Therefore, the present cost analysis is approximate and somewhat speculative since the no-fuel CAES systems share all of the problems of the conventional CAES concept in addition to special design requirements for the turbomachinery and storage facilities.

There are two important differences in the design of the turbomachinery required for a no-fuel CAES system as compared with currently available equipment. First, the compressor must be designed to operate adiabatically at outlet temperatures of $600^{\circ} \mathrm{F}$ or higher. From discussions with manufacturers, compressor outlet temperatures of this magnitude might be achieved but higher temperatures would certainly require major redesign of available equipment. None of the manufacturers contacted was able to give cost estimates for compressors of the required type.

The no-fuel CAES system turbine must operate with inlet temperatures at or near the compressor outlet temperature which is considerably lower than even the most conservative current design. Lower temperatures should greatly reduce the need for exotic materials and complex designs now required for the high inlet temperatures currently employed. However, the physical size of the system would increase and the aerodynamic design would have to be significantly altered. It is unlikely that current turbines could be suitably modified to operate efficiently at the required inlet temperatures. Again, none of the turbine manufacturers contacted would venture even a rough estimate of the cost of a suitable turbine for no-fuel CAES applications. 
Second, the storage facility for a no-fuel CAES system would be subjected to much higher temperatures than currently believed practical. In fact, previous analyses of CAES systems ${ }^{(2)}$ indicate that thermal stress in rock caverns and plastic flow in salt caverns virtually rule out either as a potential high temperature storage reservoir. Regenerative heat storage devices (such as pebble beds, fusible salts, etc.) might be used to store. heat separately from the air in conjunction with a suitable reservoir, $(7,8)$ but that subject will not be dealt with here.

The aquifer is the only alternative currently appearing attractive for direct hot air storage for CAES applications $(2,10-12)$. For temperatures approaching $700^{\circ} \mathrm{F}$, there is 1 ittle reason to expect physical or chemical processes which might damage the aquifer itself. From experience with geothermal power systems, piping and well completion procedures would be more complex and costly, but manageable. Unfortunately, limitations inherent in the present work have not permitted a study of sufficient depth to document the actual capabilities and performance which can be expected from aquifers in this application. For this reason, a detailed analysis of the fluid mechanics, thermodynamics and economics of hot air storage in aquifers is the top priority item in the planning for future work in CAES at the Pacific Northwest Laboratory (PNL).

\subsection{CAPITAL COST EQUATIONS}

The design and ultimate cost of most primary CAES system components will be directly affected by changes in the storage and turbine inlet temperatures. This study attempted to model each component's cost dependence by establishing a cost scaling equation of the form

$$
c_{i}=c_{i 0}\left(\frac{T_{s}}{T_{s o}}\right)^{m_{i}}\left(\frac{T_{f}}{T_{f o}}\right)^{n_{i}} \text {, }
$$

where $C_{i 0}$ is the installed unit cost in $\left[\frac{\$}{k W}\right]$ for component " $i$ " in the conventional CAES system (based on the conventional storage and turbine inlet temperatures $T_{\text {so }}$ and $T_{\text {fo }}$, respectively). The $C_{i 0}$ may be determined from recent literature, ${ }^{(2-4)}$ but $m_{j}$ and $n_{j}$ are determined by a combination of 
analysis and informed guess. If $m_{i}$ and $n_{i}$ are correctly determined, the model should provide a reasonably good indication of the cost trends for the hybrid system. However, the magnitude of costs thus predicted should not be taken too seriously for conditions far removed from the reference conditions, (i.e., for the no-fuel system).

The cost equations utilized for the various system components are summarized in Table 3; the definitions and numerical values of the parameters were given in Tables 1 and 2. Relevant cost data are summarized in Table 4. The detailed development and discussion of these equations is included in the appendices where the sources of the data are identified. Some of these estimates are based on relatively reliable data, some were deduced by analysis and some are primarily best judgment guesses. (a)

The capital costs consist of three principal components:

- rotating machinery, $\mathrm{C}_{r m}$

- storage facilities, $C_{s}$

- balance of plant, $C_{b p}$

The rotating machinery cost, in dollars per kW of installed capacity, is the sum of costs attributable to generators, turbines, compressors and compressor cooling apparatus.

$$
c_{r m}=C_{g}+C_{t}+C_{c}+C_{c l}
$$

The installed costs of the storage facilities in $\left[\frac{\$}{\mathrm{~kW}}\right]$ is the sum of the costs for lease of storage rights (or outright purchase), bubble development and well development, including the flow collection pipes and manifolds.

$$
c_{s}=c_{\ell}+c_{b d}+c_{w p}
$$

(a) It is expected that readers who are expert in the many diverse areas of technology upon which this work touches may find fault with some of these estimates. Indeed, constructive criticism of the data and assumptions is invited and will be gratefully received. A primary goal in future efforts at PNL will be the refinement of the models and economic data base. 
TABLE 3. Cost Equations Utilized to Analyze the Hybrid CAES Cycle

I. CAPITAL COST EQUATIONS

1) ROTATING $=$ GENERATOR + TURBINE + COMPRESSOR + COOLING

$$
C_{R M}=C_{G O}+C_{T}+C_{C}+C_{C l}\left[\frac{\$}{k W}\right]
$$

2) $\underset{\text { STORAGE }}{\text { SYSTEM }}=\underset{\text { LEASE }}{\text { AQUIFER }}+\underset{\text { DEVELOPMENT }}{\text { BUBbE }}+\underset{\text { WELL DEVELOPMENT }}{\& \text { PIPING }}$

$$
C_{S}=C_{I}+C_{B D}+C_{W P}\left[\frac{\$}{k D}\right]
$$

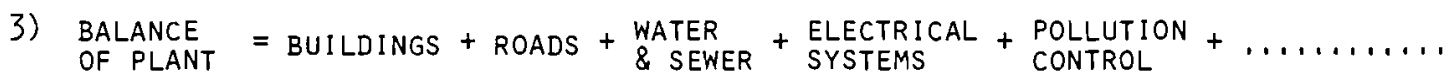

$$
C_{B P}=C_{B O} \text { (ASSUMED CONSTANT) }\left[\begin{array}{l}
\$ \\
k W
\end{array}\right]
$$

4) $\begin{aligned} & \text { TOTAL CAPITAL } \\ & \text { INVESTMENT }\end{aligned}=\begin{aligned} & \text { ROTATING } \\ & \text { MACHINERY }\end{aligned}+\begin{aligned} & \text { STORAGE } \\ & \text { FACILITIES }\end{aligned}+\begin{aligned} & \text { BALANCE } \\ & \text { OF PLANT }\end{aligned}$

$$
C_{C A P}=C_{R M}+C_{S}+C_{B P}\left[\frac{\$}{K D}\right]
$$

II. SENT-OUT POWER COSTS

1) FIXED = FIXED CHABGE RATE $\times$ INTEREST AND $\times$ CAPITAL

CHARGES $=\frac{\text { ENNUAL USE }}{\text { ANNUSCALATION } X \text { INVESTMENT }}$

$$
C_{F I X}=\frac{F C R}{U_{A}}\left[\left(1+I_{E}\right)\left(1+I_{I}\right)\right]^{Y / 2} C_{C A P}\left[\frac{M I L}{K W H}\right]
$$

2) $\begin{aligned} & \text { FUEL } \\ & \text { COSTS }\end{aligned}$

$$
C_{F U E L}=C_{F T} \theta_{T}+\frac{C_{F B}}{n_{B}}\left(\frac{W_{C}}{W_{T}}\right)\left[\frac{M I L}{K W H}\right]
$$

3) $\begin{aligned} & \text { OPERATION } \& \\ & \text { MAINTENANCE }\end{aligned}=$ SERVICES AND LABOR + REPLACEMENT + TAXES $+\ldots \ldots$

$$
C_{O+M}=C_{O M} \text { (ASSUMED CONSTANT) }\left[\frac{M I L}{K W H}\right]
$$

$\begin{aligned} & \text { 4OTAL SENT-OUT } \\ & \text { ENERGY COSTS }\end{aligned}=\begin{aligned} & \text { FIXED } \\ & \text { CHARGES }\end{aligned}+\begin{aligned} & \text { FUEL } \\ & \text { COSTS }\end{aligned}+\begin{aligned} & \text { OPERATION } \& \\ & \text { MAINTENANCE }\end{aligned}$

$$
C_{P}=C_{F I X}+C_{F U E L}+C_{O+M}\left[\frac{M I L}{K M H}\right]
$$


TABLE 4. Financial Data Used in the

Analysis of the CAES Systems

\begin{tabular}{|c|c|c|c|}
\hline Symbol & Item Description & Value & Reference \\
\hline$c_{b}$ & nuclear fuel costs & $0.43\left[\frac{\$}{10^{6} \mathrm{Btu}}\right]$ & $(2,15)$ \\
\hline$c_{f}$ & turbine fuel costs & $2.00\left[\frac{\$}{10^{6} \text { Btu }}\right.$ & $(2,15)$ \\
\hline$c_{e}$ & purchased power cost & $30\left[\frac{\mathrm{mil}}{\mathrm{kwh}}\right]$ & $(2,15)$ \\
\hline$c_{1}$ & storage lease cost & $4.00\left[\frac{\$}{\text { acre } y r}\right]$ & $(12)$ \\
\hline $\mathrm{c}_{\text {wo }}$ & $\begin{array}{l}\text { well costs for nominal } \\
\text { design conditions }\end{array}$ & $40,000\left[\frac{\$}{\text { we11 }}\right]$ & $(2,12)$ \\
\hline$c_{p o}$ & $\begin{array}{l}\text { piping costs for nominal } \\
\text { design conditions }\end{array}$ & $60,000\left[\frac{\$}{\text { we11 }}\right]$ & $(2,12)$ \\
\hline$C_{\text {go }}$ & $\begin{array}{l}\text { generator costs (includes } \\
\text { controls, fixtures and } \\
\text { accessories of the turbine } \\
\text { generator facility) }\end{array}$ & $25\left[\begin{array}{l}\$ \\
k\end{array}\right.$ & (2) \\
\hline$c_{\text {to }}$ & $\begin{array}{l}\text { turbine costs for nominal } \\
\text { design conditions }\end{array}$ & $38\left[\frac{\$}{\mathrm{~kW}}\right]$ & (2) \\
\hline$c_{\text {co }}$ & $\begin{array}{l}\text { compressor costs for nominal } \\
\text { design conditions }\end{array}$ & $19\left[\frac{\$}{k h}\right.$ & (2) \\
\hline$c_{b p}$ & balance of plant & $58\left[\frac{\$}{\mathrm{~kW}}\right]$ & (2) \\
\hline FCR & fixed charge rate & $0.18\left[\mathrm{yr}^{-1}\right]$ & \\
\hline$I_{i}$ & interest charge rate & $0.10\left[\mathrm{yr}^{-1}\right]$ & \\
\hline $\mathrm{I}_{\mathrm{e}}$ & inflation escalation rate & $0.06\left[\mathrm{yr}^{-1}\right]$ & \\
\hline$y$ & construction time & $3[y r]$ & \\
\hline
\end{tabular}


It is assumed here that the storage facility is leased. Bubble development includes charges for pumping the air into the ground to build the equilibrium bubble, plus the cost of heat required to heat the rock near the we11 head sufficiently to maintain constant temperature for a typical cycle.

Balance of plant costs, $C_{b p}$, include many items which must be paid for in establishing the facility. These costs are assumed independent of the particular design employed. Examples of items covered in this category include purchase of the site, roads, sewer and water, buildings, transformers, switching yards, fuel storage, pollution control apparatus, etc. The value of $C_{b p}$ for this analysis is based on References 2 and 9.

Total capital costs are given by

$$
c_{\text {cap }}=C_{r m}+C_{s}+C_{b p} \text {, }
$$

which, for the conventional CAES, comes out to about $88\left[\frac{\$}{\mathrm{~kW}}\right]$ based on the analys is in Reference 2.

The busbar power costs are computed by summing charges for fuel, capital, operation and maintenance. The fuel charges include costs for turbine fuel and for electrical energy consumed by the compressors. Because the storage plant is built to utilize excess capacity in the base plant, only replacement fuel costs are included for the charging power. Fuel costs in $\left[\frac{\mathrm{mi}}{\mathrm{kWh}}\right]$ are then given by

$$
c_{\text {fuel }}=c_{f t} Q_{t}+\frac{c_{f b}}{n_{b}}\left(\frac{W_{c}}{W_{t}}\right) .
$$

The fuel costs $c_{f t}$ and $c_{f b}$ are given in Table 4 and $n_{b}$ is given in Table 1. $Q_{t}$ is the turbine heat rate in $\left[\frac{B t u}{k W h}\right]$ and $\left(W_{c} / W_{t}\right)$ is the compressor power input or "heat rate" in $\left[\frac{\mathrm{Btu}}{\mathrm{kWh}}\right]$ based on the turbine output. In practice, it might be more reasonable to insist that $c_{f b}$ be increased somewhat to reflect costs of producing the charging power, but this analysis follows previous practice and charges only replacement cost.

To figure fixed charges attributable to capital, costs of interest and escalation during construction of $I_{i}=10 \%$ and $I_{e}=6 \%$ are included assuming 
construction over a period $Y=3$ years. Using a fixed charge rate (FCR) of $18 \%$ and an annual use $\left(U_{a}\right)$ of 2000 [hr/yr], the fixed charges are given approximately by

$$
c_{\text {fix }}=\frac{F C R}{U_{a}}\left[\left(1+I_{i}\right)\left(1+I_{e}\right)\right]^{y / 2} c_{c a p} .
$$

Operation and maintenance charges should probably reflect the complexity of the machinery. However, O\&M costs are relatively small, so any effects due to variation of 0\&M charges will not be important. Therefore, a constant value is assumed for 0\&M reflecting past experience with gas turbine equipment. An 0\&M charge of $3.6\left[\frac{\mathrm{mil}}{\mathrm{kWh}}\right]$ as recommended by Unsworth ${ }^{(4)}$ is used here.

Finally, the total busbar power costs are represented by the equation

$$
c_{p}=C_{\text {fix }}+C_{\text {fuel }}+C_{\text {om }} \text {. }
$$

The first two terms in this equation depend on the particular cycle chosen, i.e., the compression and expansion ratios, the storage temperature, the turbine inlet temperature, the losses in storage, and the component efficiencies. The main variables for the analysis are $T_{S}$ and $T_{f}$ but other parameters such as well deliverability, fuel costs and duty cycle are also treated as variables.

\subsection{ECONOMIC ANALYSIS RESULTS}

Power costs predicted by the hybrid model for the nominal design with variable storage temperature $T_{S}$ and firing temperature $T_{f}$ are illustrated in Figures 9-12. First, from Figure 9, power costs decrease with increasing $T_{f}$ or decreasing $T_{s}$. However, costs are relatively insensitive to $T_{f}$, especially at lower values of $T_{S}$. This suggests little incentive to drive the turbines at high firing ternperatures (i.e., high heat rate) since very little cost gain can be achieved. In fact, if the increased equipment life and reduced maintenance costs could be more accurately specified, it is conceivable that lower firing temperatures might result in lower costs. Reducing firing temperatures (and thus heat rates) to levels below current 


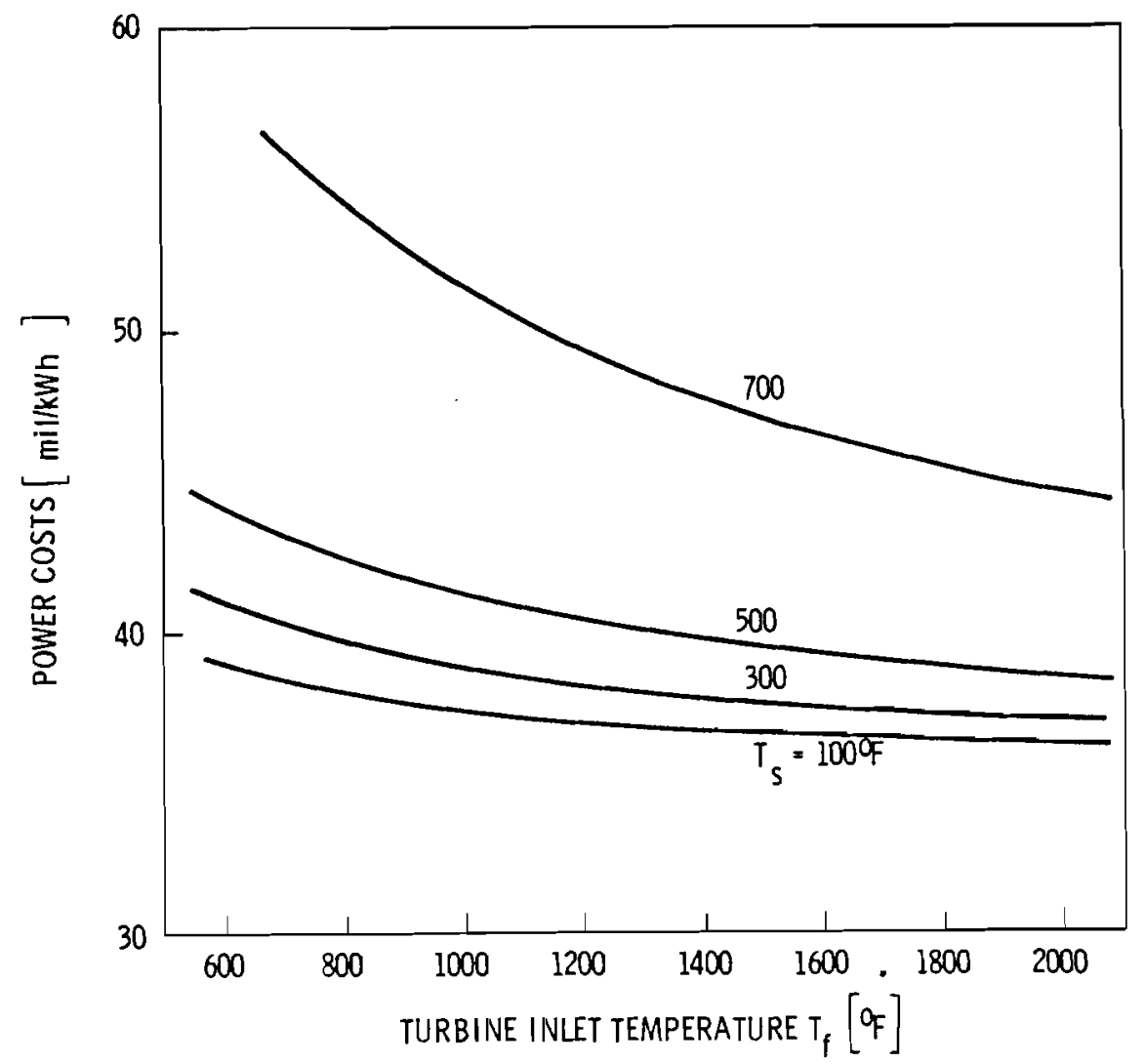

FIGURE 9. Hybrid CAES System Power Costs: Storage Temperature Effects

practice certainly deserves more study independently of its direct application to no-fuel systems.

The reasons for the cost insensitivity on $T_{f}$ are illustrated by the cost breakdowns in Figures 10 through 12. From Figure 10, considering first the bar charts corresponding to $100^{\circ} \mathrm{F}$ storage, decreasing costs for compressor power and capital charges are offset by increasing turbine fuel costs. A similar progression occurs for $T_{S}=700^{\circ} \mathrm{F}$, but cost variations do not compensate as we11, giving greater sensitivity to $T_{f}$ at higher storage temperatures. Figure 10 shows that costs are dominated by the capital fixed charges.

Figures 11 and 12 illustrate the installed costs for the capital equipment. Costs for the rotating machinery and balance of plant dominate the capital costs, especially at low storage temperatures where storage costs 


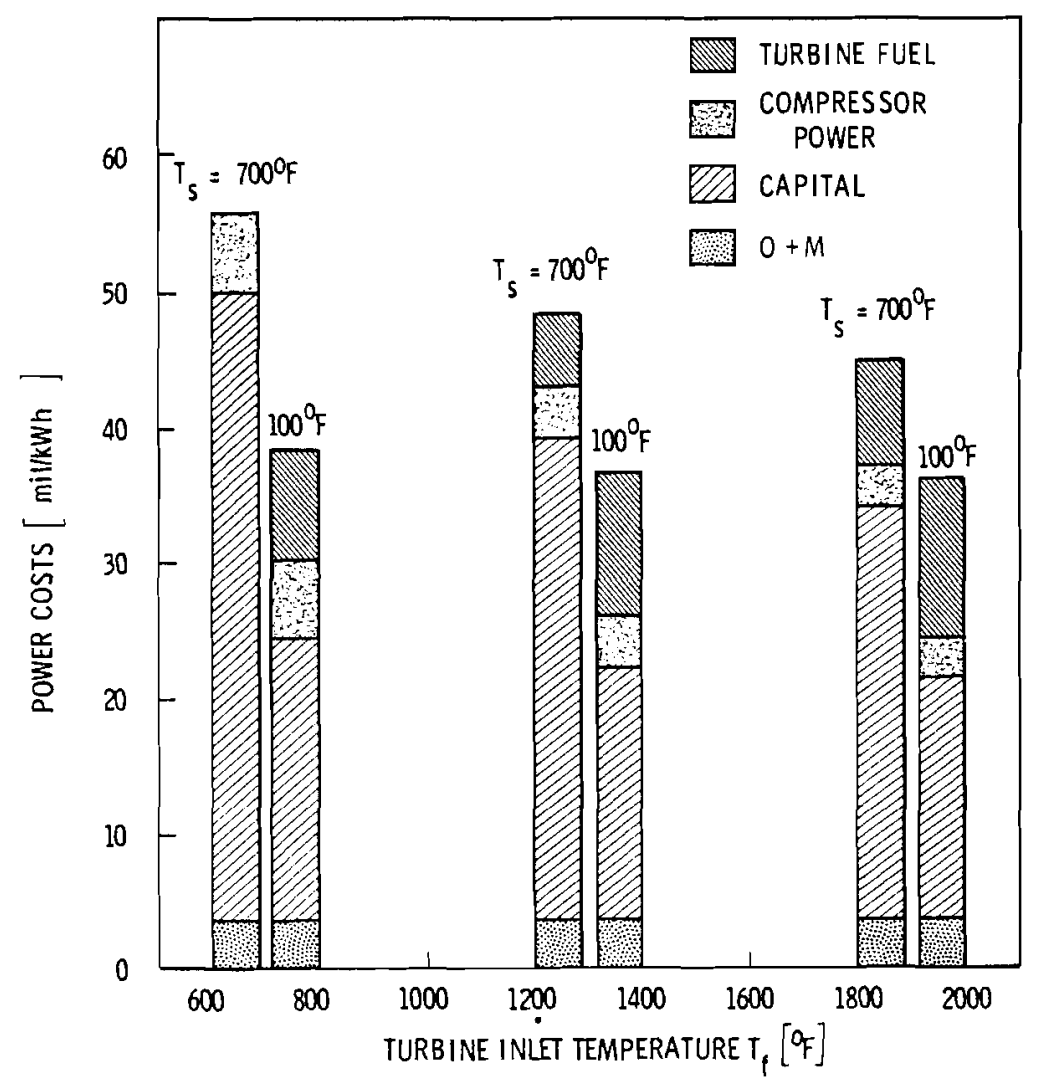

FIGURE 10. Hybrid CAES System

Power Costs Distribution

are almost negligible. The greatly increased cost of the storage facilities at higher storage temperature is due to the greater volume which must be pumped up and heated to operating conditions and increased costs for pipe, insulation, seals and well completion. Storage costs increase with decreasing firing temperature because the turbine specific output decreases. This in turn requires a larger volume flow rate, a larger storage volume, and resultant higher storage costs.

Figure 9 illustrates that power costs increase with $T_{S}$ but that the rate of increase is not severe because of counterbalancing cost variations as described in the previous paragraph. The large increase in costs between $T_{S}=500^{\circ} \mathrm{F}$ and $700^{\circ} \mathrm{F}$ is due to the assumption that a totally new and more costly compressor design would be required at about $T_{S}=600^{\circ} \mathrm{F}$. 


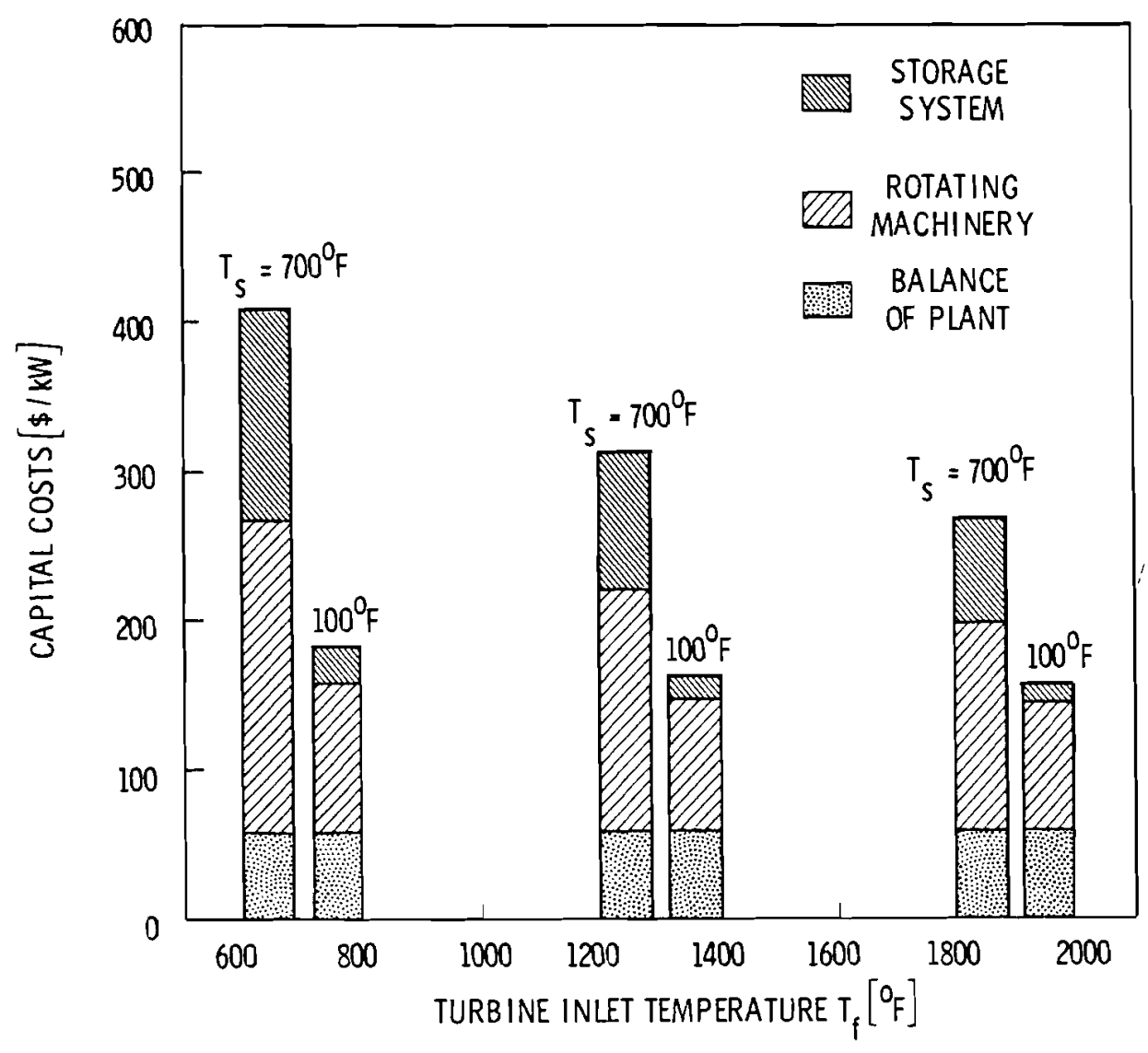

FIGURE 11. Hybrid CAES System Capital Costs Distribution

Up to $T_{S}=600$, relatively minor changes were assumed adequate and the higher temperatures were assumed accommodated by larger compressors with less cooling apparatus. The concept of a step change at some limiting temperature $\left(600^{\circ} \mathrm{F}\right.$ in the analysis) is $i 11$ ustrated by Figure 9 but the magnitude of the increased cost and the actual temperature at which it occurs are speculative and should not be taken literally.

A number of details and assumptions made in arriving at the data i11ustrated in Figures 9-12 require emphasis. First, the analysis assumes an aquifer is used for storage, and costs determined are strongly influenced by this assumption. If another reservoir were used in conjunction with a regenerator, totally different costs might be obtained; it is not clear how the results or conclusions would be altered. 


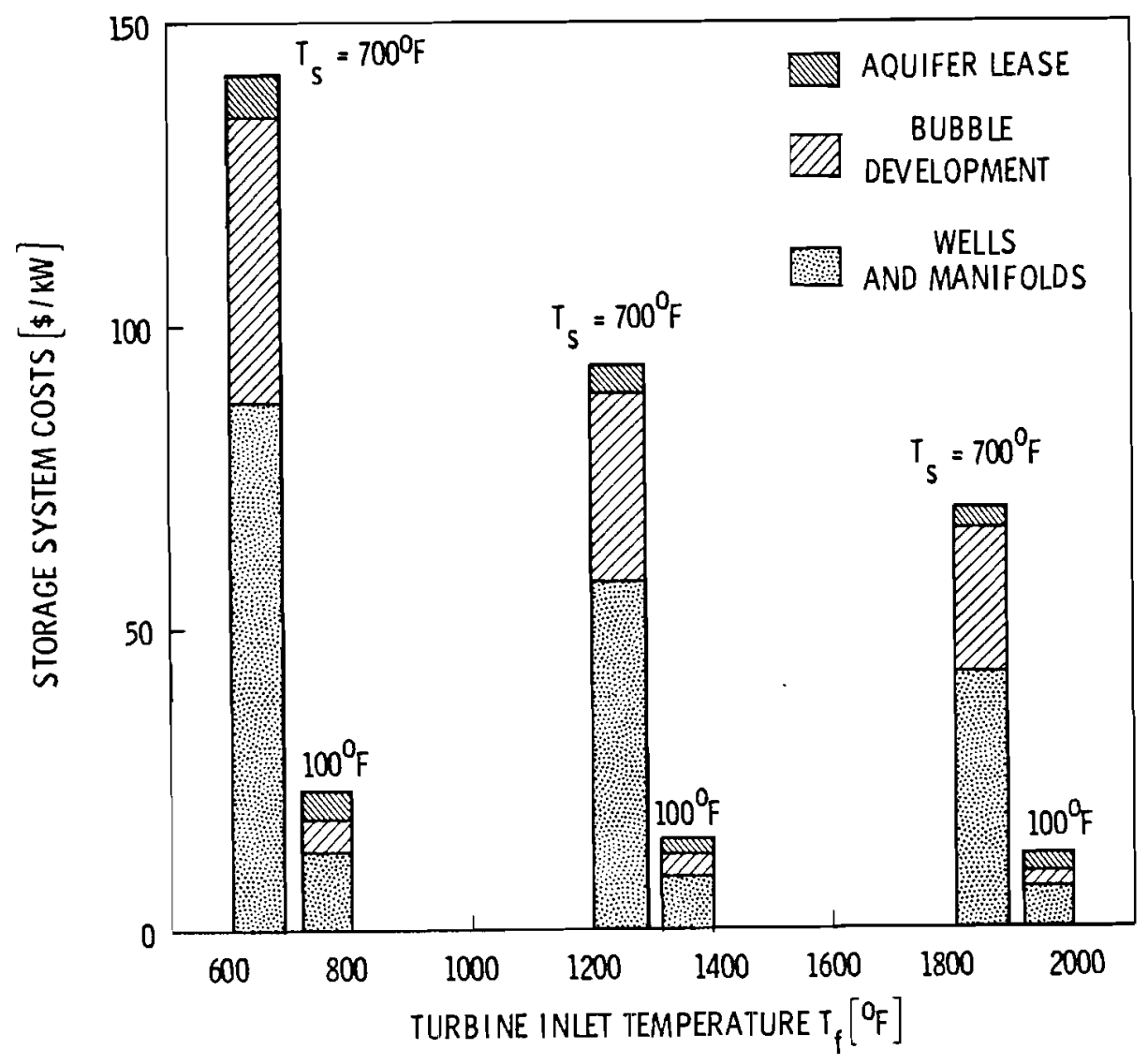

FIGURE 12. Hybrid CAES System Storage Costs Distribution

Second, the costs included for bubble development are the major costs for the storage system. Costs of pumping the air into the ground were included, plus a charge for heat required to heat up the rock containing one daily cycle volume of air. This is perhaps an arbitrary choice but it is certainly not necessary to heat up the entire reservoir volume since the area near the well acts as a very effective regenerator. The heat-up of the reservoir as an initial capital cost was included when, in fact, it would be accrued as an operating cost during the first several years of operation when higher average heat rates would be required. This was done primarily for convenience, but inclusion of heat-up costs as a capital expenditure is defensible in its own right.

The data in Figure 13 were calculated to assess the effects of the aquifer permeability on power costs. The parameter utilized is the well 


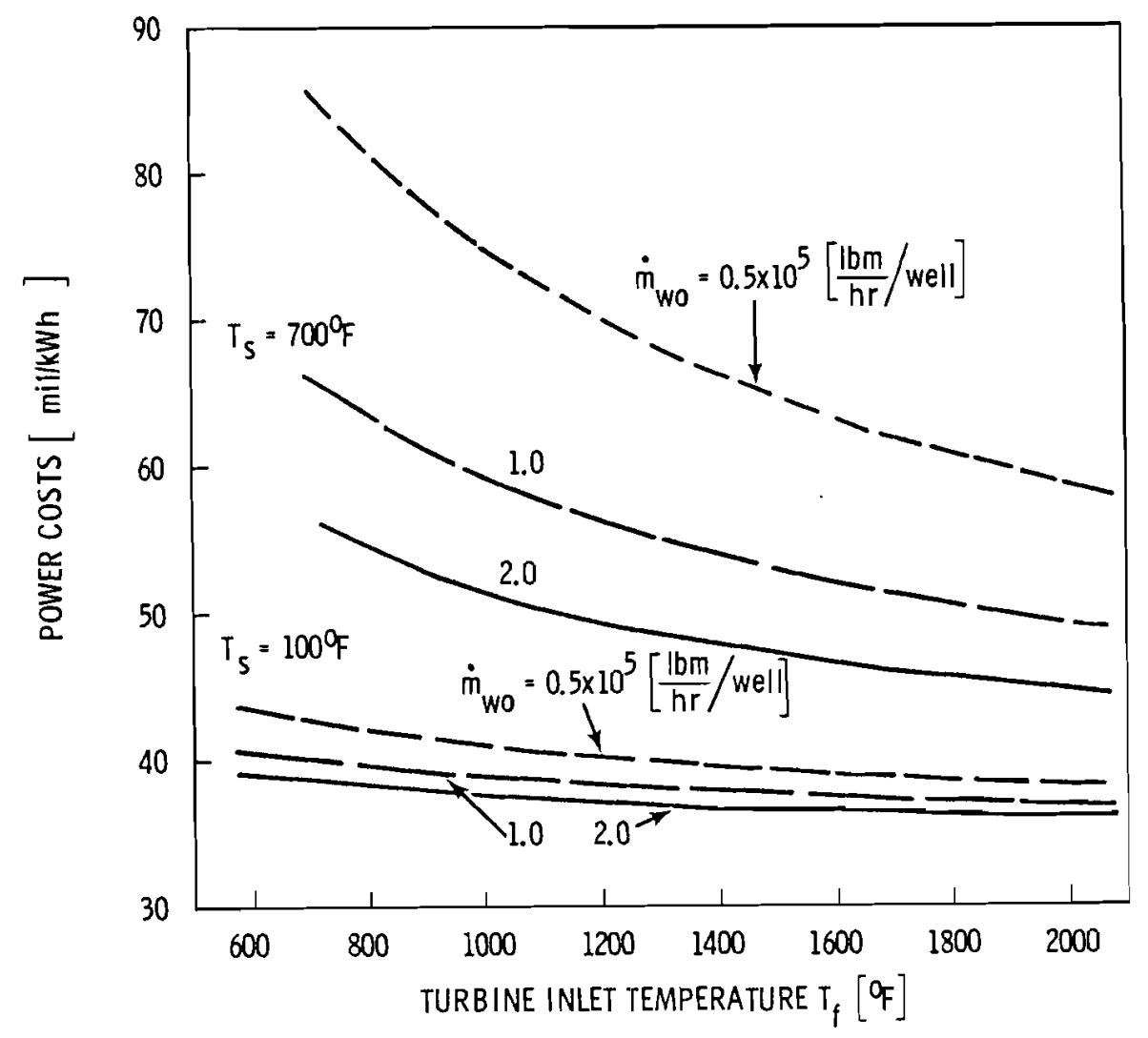

FIGURE 13. Effect of Well Deliverability (or Aquifer Permeability) on Power Costs

deliverability $\dot{m}_{\text {wo }}\left[\frac{1 b_{m} / h r}{w e 11}\right]$ where the numbers correspond to the flow rate which would exist at the nominal storage pressure $\mathrm{P}_{\text {so }}$, pressure drop $\Delta \mathrm{p}_{\text {so }}$ and storage temperature $T_{\text {so }}$. Assuming the well design is such that the pressure drop is primarily in the aquifer, the values of $\dot{m}_{w o}$ in Figure 13 correspond to increased aquifer permeability where $0.5 \times 10^{5}$ to $2.0 \times 10^{5}$ $\left[\frac{1 b_{m} / h r}{w e 11}\right]$ correspond approximately to 0.5 to 2.0 Darcy. For storage at $100^{\circ} \mathrm{F}$, the cost reduction obtained with higher deliverability is not great because storage costs are such a small fraction of total costs for these conditions. At $700^{\circ} \mathrm{F}$, storage costs are a larger fraction of the total so that cost reductions due to increased permeability are more significant. 
Figures 14 and 15 illustrate how relative fuel costs affect the analysis. From Figure 14, for storage at $100^{\circ} \mathrm{F}$ and a turbine fuel cost of $2\left[\frac{\$}{\mathrm{MBt}}\right]$, doubling the cost of nuclear fuel from $0.43\left[\frac{\mathrm{mil}}{\mathrm{kWh}}\right]$ to $0.86\left[\frac{\mathrm{mil}}{\mathrm{kWh}}\right]$ causes an increase of about 3 to $5\left[\frac{\mathrm{mil}}{\mathrm{kWh}}\right]$ in power costs. However, costs remain quite insensitive to changes in the turbine firing temperature. At $4.0\left[\frac{\$}{M B t u}\right]$ for turbine fuel and $0.86\left[\frac{\$}{M B t u}\right]$ for nuclear fuel, costs are about $10\left[\frac{\mathrm{mil}}{\mathrm{kWh}}\right]$ higher than the first case with about the same sensitivity on $T_{f}$. However, with turbine fuel at $4\left[\frac{\$}{\mathrm{MBtu}}\right]$ and nuclear fuel at 0.86 $\left[\frac{\$}{M B t u}\right]$ the slope of the cost curve is positive which means power costs are actually descreased by decreasing $T_{f}$ (or equivalently by decreasing the turbine heat rate). In any case, operation of the turbines at low inlet temperatures appears quite attractive particularly when cold storage is employed.

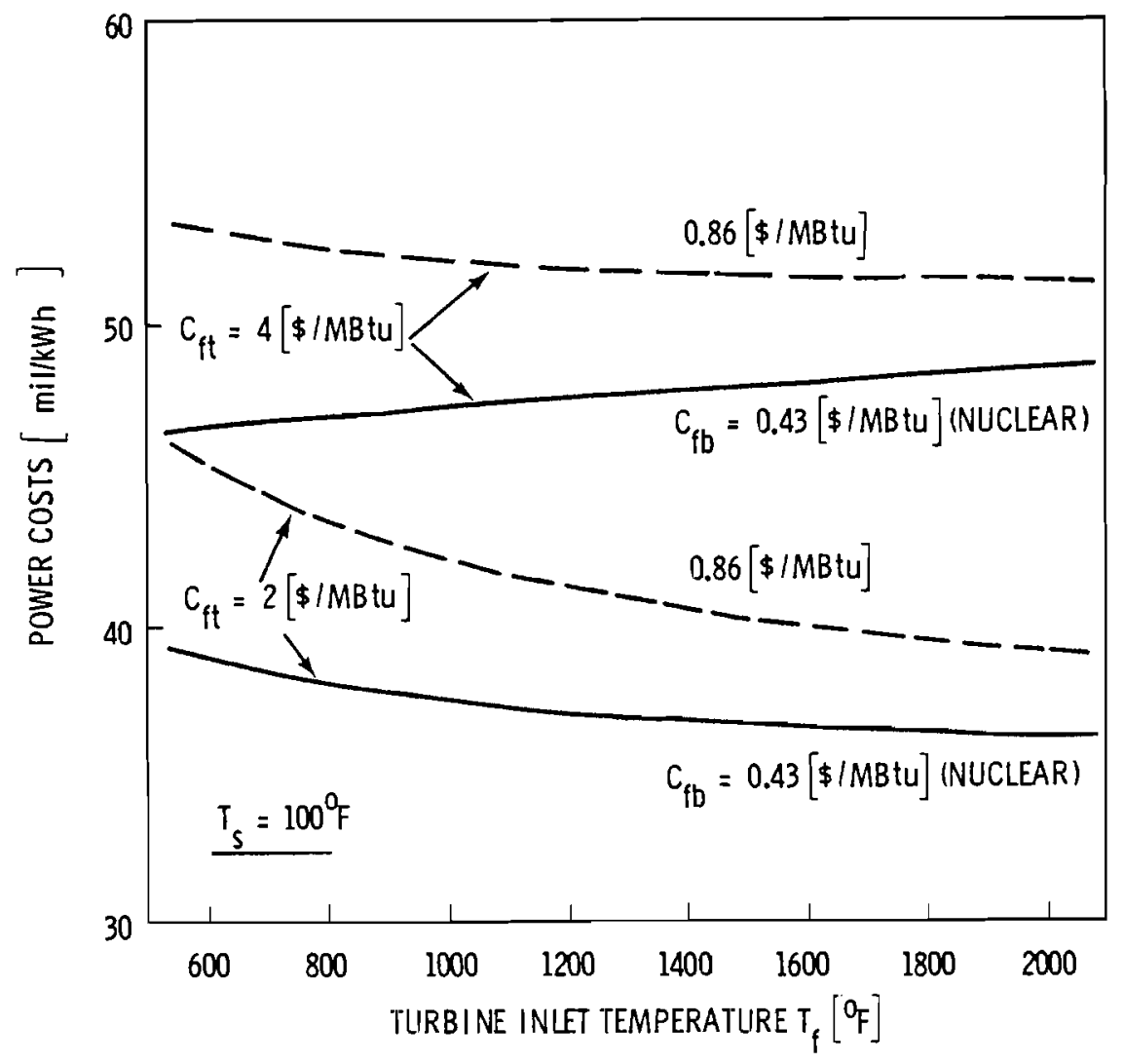

FIGURE 14. Effects of Relative Costs for Turbine Fuel and Nuclear Fuel for $100^{\circ} \mathrm{F}$ Storage 


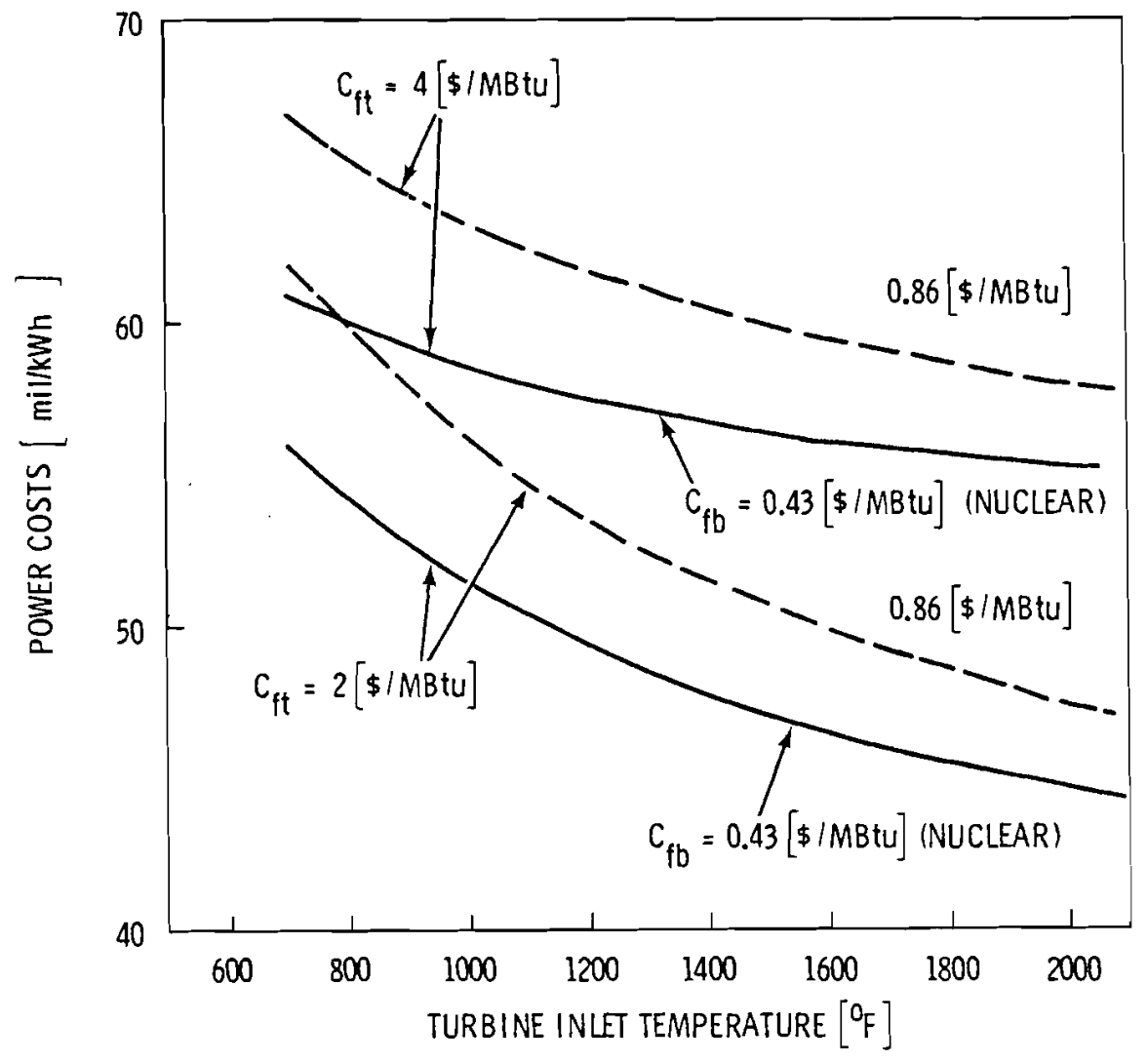

FIGURE 15. Effects of Relative Costs for Turbine Fuel and Nuclear Fuel for $700^{\circ} \mathrm{F}$ Storage

Figure 15 presents the results of the analysis for power costs as a function of relative fuel costs for a storage temperature of $700^{\circ} \mathrm{F}$. As noted above, total busbar costs are higher at the higher temperature for any particular combination of fuel costs. As shown in Figure 15, the power costs are lowest and the sensitivity to firing temperature is highest for the lower turbine fuel cost value. The conclusion is that no-fuel CAES does not appear economic at $2\left[\frac{\$}{M B t u}\right]$ for turbine fuel since costs decrease with increasing $T_{f}$.

At $4\left[\frac{\$}{M B t u}\right]$ and $700^{\circ} \mathrm{F}$ storage, total costs are higher but the dependence of the power costs on $T_{f}$ is much reduced. For example, at $4\left[\frac{\$}{M B t u}\right]$ for turbine fuel and $0.43\left[\frac{\$}{M B t u}\right]$ for nuclear fuel, the difference in cost for power 
generated by a no-fuel CAES (i.e. where $T_{f}=T_{S}=700^{\circ} \mathrm{F}$ ) and a hybrid fired at $1900^{\circ} \mathrm{F}$ is only about $6\left[\frac{\mathrm{mil}}{\mathrm{kWh}}\right]$. This is sufficiently close to tentatively conclude that no-fuel CAES can be competitive with a conventional, fueled CAES employing storage at the same temperature if the costs for turbine fuel and nuclear fuel differ by about an order of magnitude. However, the analysis also shows that power is produced for least cost using conventional CAES with cold storage. Therefore, no-fuel CAES does not appear economically attractive unless special circumstances justify its use or if turbine fuel costs increase significantly beyond what is considered here.

Finally, the effects of altering the duty cycle or annual use factor are shown in Figure 16. Costs increase quite significantly with reduced use due to the high proportion of capital costs to fuel costs. It is thus important to design for as much use as possible within the constraints peculiar to peaking duty.

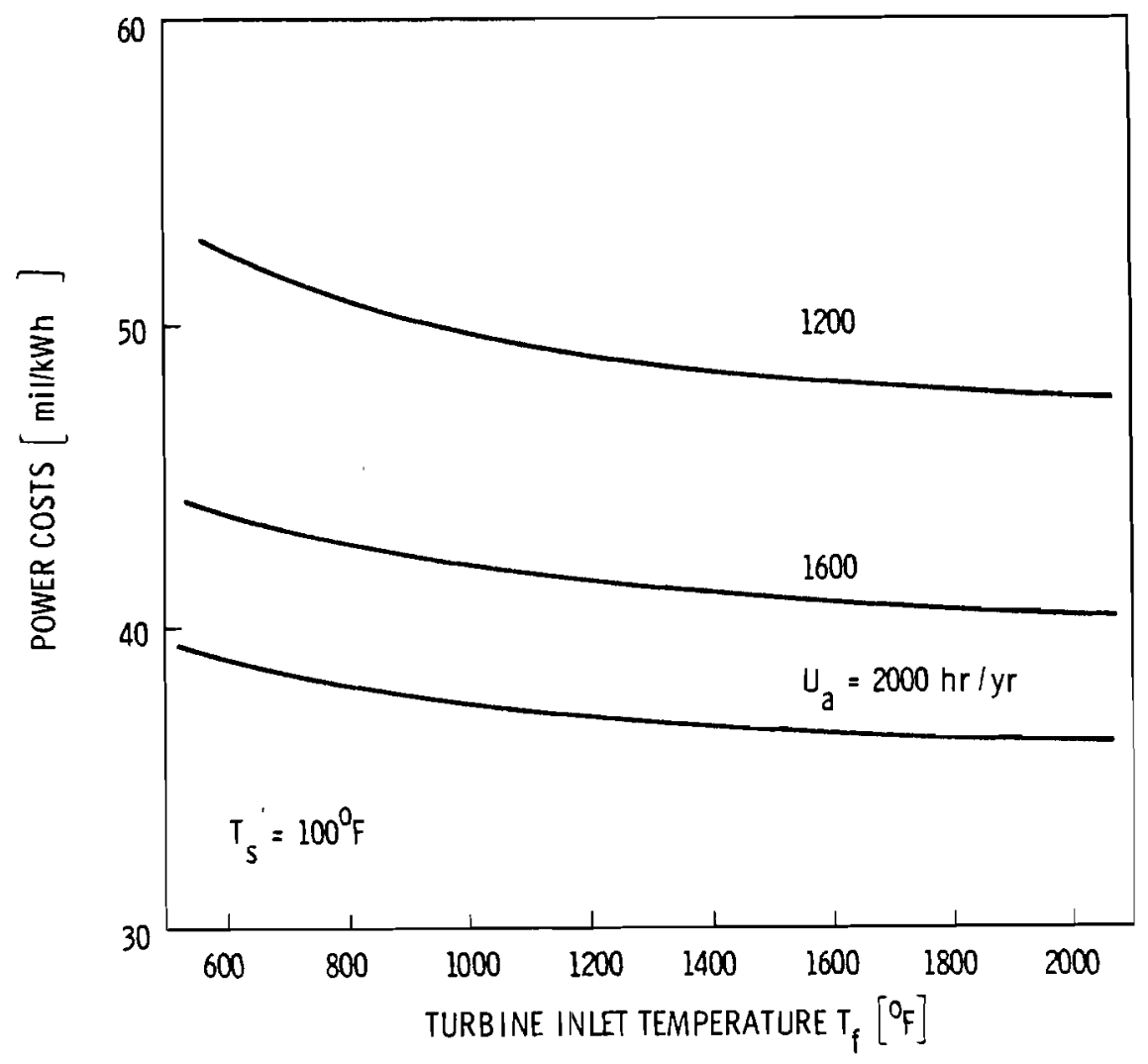

FIGURE 16. Effect of Duty Cycle on Power costs 


\subsection{CONCLUSIONS AND RECOMMENDATIONS}

\subsection{CONCLUSIONS}

The principal goal of this study was to evaluate the technical and economic feasibility of no-fuel CAES concepts for utility peaking applications. The primary conclusions may be summarized as follows:

- The analysis uncovered no insurmountable problems to preclude the technical feasibility of the no-fuel CAES concept.

- The results of the economic analysis are sufficiently unfavorable to conclude that no-fuel CAES technology could not compete with conventional CAES or standard gas turbine peaking facilities for conditions foreseeable at this time.

A number of secondary conclusions may be inferred from the analysis results. While not exclusively relevant to no-fuel systems, they are sufficiently interesting to merit further comment. These are:

- Efficient storage of the heat of compression is essential to the feasibility of the no-fuel CAES concept.

- The only available storage reservoir capable of direct high temperature storage of compressed air appears to be the aquifer. other storage media suitable for ambient storage only would have to be used in conjunction with a regenerative heat storage device.

- Although the cost difference is insufficient to be conclusive, the economics of high temperature storage indicate that fuel cost reductions potentially achievable by storage of the heat of compression are more than offset by increased capital costs for the compressors and storage facilities. Therefore, storage of the heat of compression, although energy conservative in the overall sense, appears to be economically counterproductive. 
- Because the overall cost is capital intensive, the sent-out costs for power produced from storage were very nearly insensitive to the turbine inlet temperature (or heat rate). This suggests that it may be practical to operate conventional, oil or gasfired CAES facilities at heat rates significantly reduced from previous assumed values, achieving turbine fuel savings, reduced maintenance and increased turbine life.

\subsection{RECOMMENDATIONS}

The primary contribution of the work reported here will probably be the identification of some key problems in no-fuel CAES, as opposed to the actual numerical results produced by the analysis. Therefore, the results and conclusions presented here should be treated as the first iteration in the continuing analysis of the broader subject of advanced CAES concepts and not as the final answer on the feasibility of no-fuel CAES technology. Critical topics touched on in this study, but which deserve a more detailed analysis, are shown below in approximate order of significance.

- Considerable refinement of cost data is required, especially for turbines and compressors. Toward this end, close cooperation with the manufacturers will be essential since significant design modifications may be required.

- Dynamic models of the thermodynamics, fluid mechanics and economics of ambient and high temperature air storage in aquifers should be developed. The reservoir cyclic response is particularly important because it bears heavily on the design of the surface facility and the way in which the system can be interfaced with the existing production facilities.

- Detailed models of the thermodynamics, fluid mechanics and economics of regenerative heat storage devices for CAES applications should be developed.

- Field tests of the dynamic response of an actual aquifer should be performed as soon as possible. 
- Utilization of alternative fuels for CAES applications should be investigated. In particular, gasified coal would seem to be a prime candidate.

- Utilization of CAES technology for solar and wind power applications should be investigated. 


\section{REFERENCES}

1. W. Mattick, 0. Weber, Z. S. Stys, and H. G. Haddenhorst, "Huntorf-The World's First 290 MW Gas Turbine Air Storage Peaking Plant." Proceedings, American Power Conference, Illinois Institute of Technology, Chicago, IL, April 1975.

2. J. B. Bush, Jr., et al., Economical and Technical Feasibility Study of Compressed Air Energy Storage. C00-2559-1/SRD-76-0037, General Electric Company, Schenectady, NY, March 1976.

3. An Assessment of Energy Storage Systems Suitable for Use by Electric Utilities. Study conducted for the Energy Research and Development Administration and the Electric Power Research Institute, 1976.

4. G. N. Unsworth, A Review of Pumped Energy Storage Schemes. AECL-4926, Whiteshell Nuclear Research Establishment, Pinawa, Manitoba, Canada, July 1975.

5. Henrik Harboe, Importance of Coal for Heat and Power Generation. Report No. 354E04.74, Second Edition, Stal Laval, Ltd., Finspong, Sweden, 1974.

6. L. K. Mudge, G. F. Schiefelbein, C. T. Li and R. H. Moore, The Gasification of Coal. Battelle Energy Program Report, Battelle, Pacific Northwest Laboratories, Richland, WA., July 1974.

7. I. Glendenning, Compressed Air Energy Storage by Incorporating Heat Storage, Technical Disclosure Bulletin No. 235, Central Electricity Generating Board, Marchwood, Southampton, 504 42B, England, 1974.

8. T. Stephens, "Adiabatic Compressed Air Energy Storage." Paper presented at the ERDA CAES Workshop, Airl ie House, VA, December 1975.

9. F. R. Biancardi, G. T. Peters, and A. M. Landerman, Advanced Nonthermally Polluting Gas Turbines in Utility Applications. 16130DNE03/71, Water Pollution Control Research Series, United Aircraft Research Laboratories, East Hartford, CT, March 1971.

10. D. L. Ayers, and D. Q. Hoover, "Gas Turbine Systems Using Underground Compressed Air Storage." Proceedings, American Power Conference, Illinois Institute of Technology, Chicago, IL, 36: 384, $197 \overline{4}$.

11. D. L. Ayers and R. E. Strong, "Compressed Air Energy Storage-Another Answer to the Peaking Problem." Power Engineering. 79: 36-39, 1975.

12. W. F. Lang, "Underground Energy Storage for Electrical Power Generation." Proceedings of the Fourth Symposium on Salt, Northern Ohio Geological Society, Cleveland, OH, 1974, pp. 323-327.

13. R. J. M. DeWiest, ed., Flow Through Permeable Media. Academic Press, New York, NY, p. 70, $196 \overline{69}$.

14. R. C. Weost, ed., Handbook of Tables for Appl ied Engineering Science. The Chemical Rubber Co., Cleveland, $\mathrm{OH}$, p. 9, 133, 1970. 


\section{REFERENCES (Continued)}

15. V. de Biasi, "FY-50 Design Shortcut to 1980 Technology." Gas Turbine World. pp. 9-17, 1975.

16. W. J. Lang, "Compressed Air Storage Considerations For Reef-Type Aquifer Structures in Indiana." Paper presented at the ERDA CAES Workshop, Airlie House, VA, December 1975.

17. C. H. Bloomster, "Economic Analys is of Geothermal Energy Costs." BNWL-SA-5596, presented to the American Institute of Chemical Engineers, Los Angeles, CA, November 1975. 
APPENDIX A

ROTATING MACHINERY COSTS 


\section{APPENDIX A}

\section{ROTATING MACHINERY COSTS}

\section{A. 1 TURBINE COST EQUATION}

The cost of the turbine in $\left[\frac{\$}{\mathrm{~kW}}\right]$ is a function of the size of the machine and the degree of sophistication required in the design. Both factors are affected by the firing temperature so that the actual cost dependence on $T_{f}$ is difficult to predict. To assess these effects, we start with the equation for the turbine specific work $\left[\frac{B t u}{1 \mathrm{bm}}\right]$,

$$
w_{t}=n_{t} C_{p} T_{f}\left(r_{t}^{n}-1\right)=w_{t o}\left(\frac{T_{f}}{T_{f o}}\right) \text {. }
$$

We then consider the ratio of the turbine works for two turbines fired at $T_{1}$ and $T_{2}$ for the same efficiency, pressure ratio and power output:

$$
\begin{aligned}
1.0 & =\frac{\dot{m}_{1} W_{t 1}}{m_{2} W_{t 2}} \\
& =\frac{A_{1} V_{1} \rho_{1} T_{1} C_{p}}{A_{2} V_{2} p_{2} T_{2} C_{p}\left(r_{t 1^{n}}^{n}-1\right) n_{t 1}}
\end{aligned}
$$

From the ideal gas law, $p_{1} T_{1}=p_{2} T_{2}$ and we obtain

$$
V_{1} A_{1}=V_{2} A_{2}=\text { volume flowrate }
$$

In conclusion, the same volumetric flowrate is required to produce equal power at different turbine inlet temperatures. We will further assume that the aerodynamic design of the two turbines is similar and that the Mach numbers in the corresponding turbine passages are equal. The physical size of the two machines, related by the ratio of the flow areas, is then given approximately by

$$
\begin{aligned}
\frac{A_{2}}{A_{1}} & =\frac{V_{1}}{V_{2}} \approx \frac{\sqrt{\text { RTT }}}{\sqrt{\gamma R T_{2}}} \\
& \approx \sqrt{\frac{T_{1}}{T_{2}}}
\end{aligned}
$$


To estimate the cost of the turbine, we will assume that costs are proportional to the area ratio. The cost equation may be expressed approximately by

$$
c_{t}=c_{\text {to }}\left(\frac{T_{t}}{T_{\text {fo }}}\right)^{-1 / 2}
$$

where $c_{\text {to }}$ is the turbine cost in $\left[\frac{\$}{\mathrm{~kW}}\right]$ for a turbine designed to operate at the reference temperature $T_{f_{0}}$. For firing temperatures significantly lower than $T_{f o}$, equation (A-5) probably overestimates costs because it does not attempt to account for cost savings which would accrue due to the use of 1 ess sophisticated materials and design. Unfortunately, the data required to include these considerations in the cost analys is could not be obtained.

\section{A.2 COMPRESSOR COSTS}

The cost of compressors for a given power output and pressure ratio will also depend on $T_{f}$ and $T_{S}$. The compressor installed cost in terms of volume displacement capacity, $\left[\frac{\$}{\mathrm{ft}^{3} / \mathrm{hr}}\right]$, should be relatively independent of the outlet temperature up to some maximum temperature $T_{m}$, beyond which costs would increase because of special high temperature design modifications. The installed cost in terms of mass flow $C_{m}\left[\frac{\$}{1 b / h r}\right]$ should increase in proportion to the outlet temperature because the specific volume $v$ increases with $T_{S}$, requiring a larger cross sectional area for the same mass flow rate. To represent this effect we will assume that the compressor costs may be given by

$$
C_{m}\left[\frac{\$}{1 b_{m} / h r}\right] \propto v=\text { const }\left(\frac{T_{s}}{T_{s o}}\right)
$$

This says that the cost of the compressor increases proportionally with $T_{s}$ due to the increase in the size of the machine.

It is more difficult to model the cost dependence due to needed changes in design and materials which would be required for high temperature operation. To model these effects, we will multiply $C_{\mathrm{m}}$ by a scaling factor given by $\left(\frac{T_{S}}{T_{s 0}}\right)^{m}$ which gives increasing costs with increasing outlet temperature $T_{S}$. 
$T_{\text {so }}$ is the reference storage temperature at which cost data are evaluated from the literature.

It is reasonable to assume that increased outlet temperatures can be achieved simply by reducing the amount of cooling; this procedure would entail no additional costs. However, at some threshold temperature $T_{m}$, no further reduction in cooling could be accomplished without damage to the compressor or other operational problems. Thus, to go above $T_{m}$ would require a new design resulting in a substantial cost increase.

To represent these effects, we define the scaling factor as a discontinuous function by defining $m$ in the following manner:

$$
\mathrm{m}= \begin{cases}0 & \mathrm{~T}_{\mathrm{S}} \leq \mathrm{T}_{\mathrm{m}} \\ 1 & \mathrm{~T}_{\mathrm{S}}>\mathrm{T}_{\mathrm{m}}\end{cases}
$$

For the analysis, we have used $\mathrm{T}_{m}=600^{\circ} \mathrm{F}=1060^{\circ} \mathrm{R}$ and a 1 inear cost dependence, $m=1$. According to manufacturers contacted, compressor outlet temperatures approaching $500^{\circ} \mathrm{F}$ to $600^{\circ} \mathrm{F}$ might be feasible with present equipment without major modification, but no hard data is available to document this assertion. Similarly, the 1 inear cost dependence $(m=1)$ and the step cost increment at $600^{\circ} \mathrm{F}$ (roughly a factor of two) are only guesses and should not be taken literally. At any rate, these effects do not occur until $\mathrm{T}_{\mathrm{S}}$ exceeds $600^{\circ} \mathrm{F}$. For most of the conditions considered in this work, increased compressor costs are due to size increases related to variations in $T_{s}$ and $T_{f}$.

We may now write

$$
c_{m}\left[\frac{\$}{1 b_{m} / H r}\right] \propto \text { const }\left(\frac{T_{s}}{T_{s o}}\right)^{1+m}
$$

We now express this cost in terms of turbine capacity.

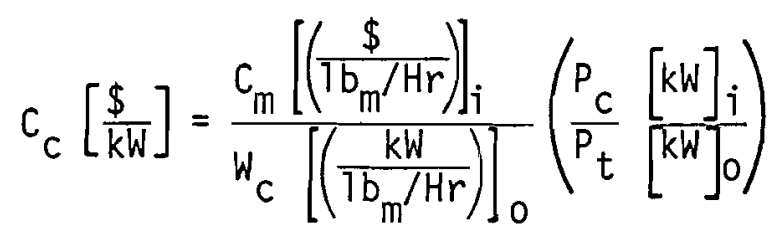

where the subscripts $i$ and $o$ here denote input and output quantities. 
Specification of the relative power ratio $P_{c} / P_{t}$ requires some very significant assumptions in terms of plant design and operation. It is apparent that the nature of the utility demand curve will have a definite impact on the design of the system. Normally there would be periods of excess capacity, designated by $\tau_{c}$, when the compressors could be run. These run times (or duty cycles) and the power levels required in each phase of operation ultimately determine the relative power required in the turbine and compressor. A cycle mass balance requires

$$
\frac{\dot{m}_{c}}{\dot{n}_{t}}=\frac{\tau_{t}}{\tau_{c}}
$$

The power ratio is then given by

$$
\frac{P_{c}}{P_{t}}=\frac{\dot{m}_{c}}{\dot{r}_{t}} \frac{W_{c}}{W_{t}}=\frac{{ }^{\tau} t}{\tau_{c}} \frac{W_{c}}{W_{t}}
$$

It is not clear how one might best specify the equipment rating and/or duty cycles for different values of $T_{f}$ and $T_{S}$. For the present analysis, we will arbitrarily assume that the utility chooses to operate for equal times, $\tau_{t}=\tau_{c}=\tau$, and that they are satisfied with whatever degree of load leveling this provides. From equations $(A-8)$ and $(A-11)$, we may now write

$$
c_{c}=\frac{c_{m}}{W_{c}}\left(\frac{W_{c}}{W_{t}}\right)=\frac{c_{m}}{W_{t}}
$$

Finally, substituting for $W_{t}$ in terms of $T_{f}$ [equation (A-1)] and $C_{m}$ in terms of $T_{s}$ [equation $(A-8)$ ] we obtain

$$
c_{c}=C_{c o}\left(\frac{T_{s}}{T_{s o}}\right)^{1+m}\left(\frac{T_{f o}}{T_{f}}\right)
$$

where $C_{\text {co }}$ represents the installed cost in $\left[\frac{\$}{k W}\right]$ for the conventional system with a firing temperature $T_{\text {fo }}$ and storage temperature $T_{\text {so }}$.

The compressor cooling apparatus represents a cost which should be included because a reduction in cooling costs with increasing storage temperature represents cost savings to potentially offset increased costs in other areas. We will represent cooling costs by an equation similar to that employed for the compressors since the amount of cooling equipment increases 
in proportion to the mass flow times the temperature change required. Thus, making the same assumptions as for the compressor costs, the cooling costs are approximated by

$$
C_{c 1} \propto C_{c l 0}\left(\frac{T_{f o}}{T_{f}}\right)\left(\frac{T_{4}-T_{s}}{T_{4}-T_{s o}}\right)\left[\frac{\$}{k W}\right]
$$

where $C_{\mathrm{clo}}$ is the cooler costs in $\left[\frac{\$}{\mathrm{~kW}}\right]$ for the conventional design. $T_{4}$ is the compressor outlet temperature assuming, for simplicity, that a11 cooling occurs in an aftercooler.

As in the case of turbine costs, we can expect to predict costs fairly well for operation near the reference conditions $T_{\text {fo }}$ and $T_{\text {so }}$. However, the means to account for the costs of needed design changes are approximate at best and are thus suitable for modeling cost trends only.

\section{A. 3 GENERATOR COSTS}

There is no reason to believe that the generator cost would vary with $T_{s}$ or $T_{f}$, so we may treat it as a constant. We will include the special costs for clutching and controls with the generators because that portion of the cost should also be constant.

\section{A. 4 COST BREAKDOWN}

We have already established estimates for the exponents in the cost scaling equations; it remains to establish cost breakdowns for the equipment associated with the conventional CAES. As a starting point we will use an installed cost of approximately $88\left[\frac{\$}{\mathrm{~kW}}\right]$ for the turbine-generator package as established in Reference 2. Of this, $25\left[\frac{\$}{\mathrm{~kW}}\right]$ will be attributed to the generator, controls, accessories, clutches, etc, , all of which are independent of the storage and turbine inlet temperatures. We allocate $38\left[\frac{\$}{\mathrm{~kW}}\right]$ to the turbines, $19\left[\frac{\$}{\mathrm{~kW}}\right]$ to the compressors and $6\left[\frac{\$}{\mathrm{~kW}}\right]$ to cooling apparatus. This relative cost breakdown is based primarily on advanced gas turbine information in Reference 9. Moderate variations in this breakdown may be made without significantly altering the results of the cost analysis. 
APPENDIX B

STORAGE SYSTEM COSTS 


\section{APPENDIX B}

\section{STORAGE SYSTEM COSTS}

\section{B.1 AQUIFER COSTS}

The total cost of the wells will be the product of the cost per well, $c_{w}$, times the number of wells, $N_{w}$. The number of wells may be given by

$$
N_{w}\left[\frac{w e 11 s}{k W}\right]=\frac{1}{\dot{m}_{w}\left[\frac{1 b / h r}{w e 11}\right] w_{t}\left[\frac{k W h}{1 b m}\right]} .
$$

Equation (A-1) gives $W_{t}$ in terms of the firing temperature $T_{f}$ but we must estimate the flow per well for different values of storage temperature $T_{S}$.

There are essentially two flow resistances, the pipe resistance and the aquifer resistance. Therefore, the total pressure drop is given by

$$
\begin{aligned}
\Delta p_{\text {tot }} & =\Delta p_{p}+\Delta p_{a} \\
& \sim f\left(\frac{L}{D}\right)_{p} \frac{\rho v^{2}}{2}+\dot{m}_{w} \frac{\mu}{\rho K_{p}}\left(\frac{L}{A}\right)_{a}
\end{aligned}
$$

The first term is the usual pipe flow equation and the second is Darcy's law. $\dot{m}_{w}$ is the mass flow rate, $\mu$ is the viscosity, $k_{p}$ the permeability and $(L / A)_{a}$ is the ratio of "effective values" of the flow path length and flow area in the aquifer. The aquifer pressure drop will normally be much larger than that in the pipes for this application so that we will neglect the first term. We may assume that the well is designed for a given $\Delta p$ and that $K_{p}\left(\frac{A}{L}\right)_{a}$ is constant. For a gas, the viscosity varies with $T$ as

$$
\mu_{s}=\mu_{s o}\left(\frac{T_{s}}{T_{s o}}\right)^{q}
$$

where $q \sim 1.66$ for air at the relevant pressure and temperature.

Finally, the mass flow rate in the aquifer may be given by

$$
\dot{m}_{w} \sim \dot{m}_{w O}\left(\frac{T_{s o}}{T_{s}}\right)^{1.66}
$$


where $m_{w 0}$ is the mass flow rate at the reference temperature $T_{\text {so }}$. This result is in good agreement with Ayers' results ${ }^{(10)}$ for air flow in an aquifer.

We may now give the number of wells as

$$
N_{w}=\left[w_{t} \dot{m}_{w 0}\left(\frac{T_{s 0}}{T_{s}}\right)^{q}\right]^{-1}=\frac{1}{\dot{m}_{w 0} W_{t}}\left(\frac{T_{s}}{T_{s o}}\right)^{q}
$$

We will assume that the cost per well increases in proportion with the absolute temperature because of various problems associated with high temperature well completion.

$$
c_{w}\left[\frac{\$}{\text { welT }}\right]=c_{\text {wo }}\left(\frac{T_{s}}{T_{s o}}\right)^{P}
$$

Experience with geothermal wells shows that costs for completing the wells increases roughly in proportion to the storage temperature. (17) For this analysis, we will thus use $p \approx 1$, although this may be somewhat low. (16) The parameter $C_{\text {wo }}$ is the cost per well for completion at the ambient reference condition $T_{s o}$. We will assume that the cost of surface pipes and manifold $C_{p}$ is also proportional to the number of wells so that the total costs of wells and piping may be given by their sum times the number of wells, or

$$
c_{w p} \simeq\left(C_{w}+C_{p}\right) N_{w}
$$

From equations $(A-1)$ and $(B-4)$ through $(B-7)$ we then obtain

$$
C_{w p}=C_{w p o}\left(\frac{T_{s}}{T_{s o}}\right)^{2.7}\left(\frac{T_{f}}{T_{f o}}\right)^{-1}
$$

where $C_{\text {wpo }}$ is the total cost for wells and piping for operation at the reference conditions $T_{\text {so }}$ and $T_{\text {fo }}$, expressed as

$$
C_{w p o}=\frac{C_{w o}+C_{p o}}{w_{\text {to }} m_{\text {wo }}}
$$

The well costs are, of course, highly dependent on the size and depth of the we11s, the nature of the strata penetrated, the geographic location and other factors too numerous to mention. For calculation, we will use 
the data generated in Reference 2; the conditions assumed in that work are similar to those of the present analysis. The actual value employed is $\$ 100,000$ per well including pipes and connectives.

\section{B.2 BUBBLE DEVELOPMENT}

We must include capital charges for energy consumed to develop the equilibrium air bubble. This will include costs for pumping the required air into the ground plus heat to bring the rock up to the equilibrium condition. The amount of air cycled per day per kW of capacity is given by

$$
\Delta M_{s}\left[\frac{1 b / d a y}{k W}\right]=\frac{\tau\left[\frac{h r}{d a y}\right]}{W_{t}\left[\frac{k W h}{1 b_{m}}\right]}
$$

where $\tau$ is the daily duty in $\left[\frac{\mathrm{hr}}{\mathrm{day}}\right]$.

Assuming a cushion factor $k_{b}\left[\frac{\mathrm{ft}^{3} \text { total }}{\mathrm{ft}^{3} / \text { day }}\right]$ the maximum stored volume per $\mathrm{kW}$ of capacity is

$$
M_{s}[1 b / k W]=k_{b} \Delta M_{s}=\approx \frac{k_{b \tau}}{W_{t}}
$$

The energy required to build the equilibrium bubble is then

$$
E_{s}\left[\frac{k W h}{k W}\right]=M_{s} W_{c}=k_{b}+\left(\frac{W_{c}}{W_{t}}\right)
$$

In addition, a considerable quantity of heat must be supplied to bring the rock up to the equilibrium temperature, and should be included in the development cost. In practice, this energy will be paid for in the form of higher turbine heat rates during the first years of operation and not as an initial expense. Nevertheless, we will include the cost of the initial heat charge as an initial capital expenditure.

It is not necessary to heat up the entire aquifer because the region around each well acts as a regenerator storing up heat during the charge 
phase and releasing heat on discharge. Without a thorough analysis of the problem, it is impossible to state precisely how much heat must be supplied to heat the rock in order to obtain the "equilibrium" operation point. For the analysis, we arbitrarily assume that a volume of rock $\Delta V_{r}$ sufficient to contain one daily cycle volume of air $\Delta V_{s}$ must be heated to a "mean storage temperature" given by

$$
T_{s m}=\frac{T_{s}+T_{0}}{2}
$$

where $T_{0}$ is the ambient rock temperature. The required rock mass is then

$$
\begin{aligned}
\Delta M_{r}\left[\frac{1 b}{k W}\right] & =\rho_{r} \Delta V_{r} \\
& =\frac{\rho_{r}}{\varepsilon_{r} \rho_{s}} \Delta M_{s}=\frac{\rho_{r}}{\varepsilon_{r} \rho_{s}}\left(\frac{\tau}{W_{t}}\right)
\end{aligned}
$$

where $\varepsilon_{r}$ and $\rho_{r}$ are the porosity and density of the rock. The bubble density $\rho_{s}$ will be calculated at the mean storage temperature $\frac{T_{s}+T_{0}}{2}$. The heat addition required for bubble development is

$$
\operatorname{Qr}\left[\frac{B t u}{k W}\right]=\frac{\rho_{r} \tau}{\varepsilon_{r} \rho_{s} W_{t}}\left(\frac{c_{p r}\left(T_{s}-T_{0}\right)}{2}\right)
$$

Assuming purchased power costs of $c_{e}\left[\frac{\mathrm{mi} l}{\mathrm{kWh}}\right]_{e}$ and fuel costs of $c_{f t}\left[\frac{\mathrm{mil}}{\mathrm{kWh}}\right]_{t}$, we obtain the total bubble development cost as the sum of pumping and heating costs,

$$
c_{b d}\left[\frac{\$}{k W}\right]=\frac{c_{e} k_{b} W_{c}}{W_{t}}+\frac{c_{f t}{ }^{\rho} r^{\tau}}{\varepsilon_{r} \rho_{s} W_{t}}\left[\frac{c_{p r}\left(T_{s}-T_{0}\right)}{2}\right]
$$

\section{B.3 LAND COSTS}

A certain amount of land must be purchased for construction of the surface facilities. This cost will be relatively small and will be assumed to be part of the balance of plant costs. The storage volume can be leased or purchased; in either case, alternative uses such as farming may be continued. We will assume the land is leased at a cost of $c_{s 1}=4\left[\frac{\$}{\text { acre } y r}\right]$. The 
lease cost is given by

$$
\begin{aligned}
& C_{1}\left[\frac{\$}{\mathrm{~kW}}\right]=\frac{c_{s 1}\left[\frac{\$}{\mathrm{acre}} \mathrm{yr}\right] M_{s}\left[\frac{1 \mathrm{bm}}{\mathrm{kW}}\right]}{F C R\left[\frac{\%}{\mathrm{yr}}\right] \rho_{s}\left[\frac{1 \mathrm{bm}}{\mathrm{ft}^{3}}\right] \mathrm{v}_{\mathrm{s}}\left[\frac{\mathrm{ft}}{\mathrm{acre}}\right]} \\
& =\frac{c_{s} 1}{F C R}\left(\frac{k_{b} \tau}{\rho_{s} V_{s} W_{t}}\right)
\end{aligned}
$$

In equations $(B-17), V_{s}$ is the storage capacity of the aquifer in $\left[\frac{\mathrm{ft}^{3}}{\mathrm{acre}}\right]$ which depends on the thickness and porosity of the storage zone. The density $\rho_{s}$ is proportional to $1 / T_{s}$ by the ideal gas 1 aw and $W_{t}$ is proportional to $T_{f}$ by equation $(A-1)$. Thus, equations $(B-16)$ and $(B-17)$ can be expressed directly as functions of $\left(\frac{T_{S}}{T_{s o}}\right)$ and $\left(\frac{T_{f}}{T_{f o}}\right)$, similar to equations $(A-5)$ and $(A-6)$; however, there is no need to do so at this time. Values used for the various design parameters in the above equations are summarized in Table 2 in the main text. Cost equations are summarized in Table 3 and pertinent financial data are found in Table 4.

Where possible, data sources are identified in the tables. However, many of the costs are based on little more than educated guesses. We thus re-emphasize the need for caution in interpreting these results for conditions far removed from the nominal design from which costs were estimated. 
APPENDIX C

NOMENCLATURE 


\section{APPENDIX C}

\section{NOMENCLATURE}

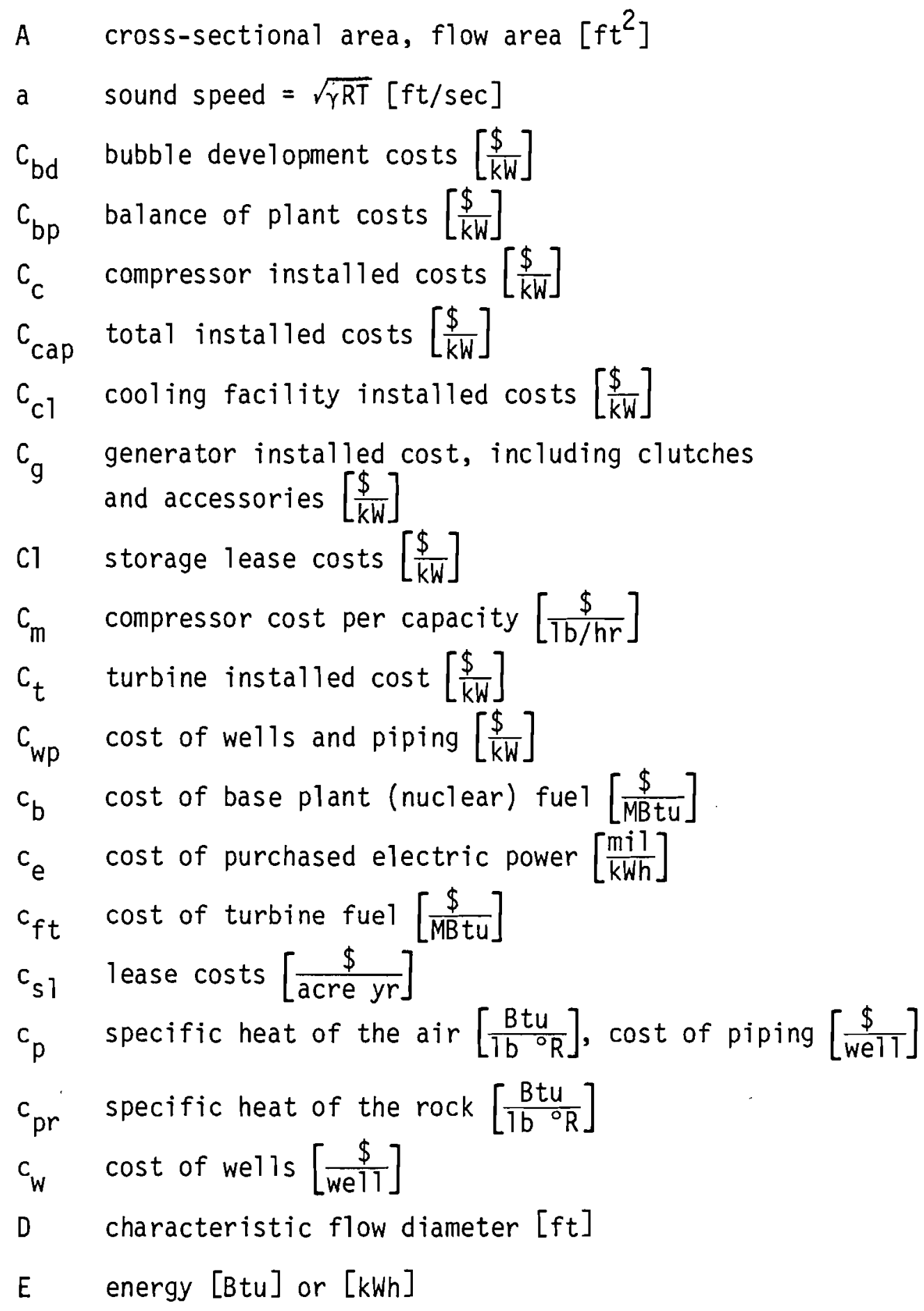


FCR fixed charge rate $\left[\frac{\$}{y r}\right]$

$f$ friction factor

$h \quad$ enthalpy of the air $\left[\frac{B t u}{1 b}\right]$

$I_{e} \quad$ cost escalation by inflation during construction $\left[\frac{\%}{y r}\right]$

$I_{i} \quad$ interest during construction $\left[\frac{\%}{y r}\right]$

$k_{p} \quad$ permeability of the aquifer [Darcy]

$k_{b}$ bubble cushion factor

$k_{t}$ ratio of compressor run time to turbine run time

$L \quad$ characteristic flow length $[\mathrm{ft}]$

$M_{C}$ specific mass flow of the compressor $\left[\frac{1 \mathrm{~b}}{\mathrm{kWh}}\right]$

$M_{S}$ total mass of air stored [1b]

$\Delta M_{s} \quad$ mass cycled per day $\left[\frac{1 b}{\text { day }}\right]$

$M_{t} \quad$ specific mass flow of turbine $\left[\frac{1 b}{k W h}\right]$

$m$ mass flow rate $\left[\frac{1 b}{s e c}\right]$

$m_{w} \quad$ mass deliverability of a well $\left[\frac{1 \mathrm{~b} / \mathrm{hr}}{\mathrm{wel1}}\right]$

$\mathrm{N}_{\mathrm{w}}$ number of wells

$n$ adiabatic coefficient $=(\gamma-1) / \gamma$, exponent in a cost equation

o subscript o denotes properties of the "nominal" design for ambient storage and fired high temperature turbines

$P \quad$ pressure $\left[\frac{1 b}{i n^{2}}\right]$, Power $[k W]$

p an exponent in a cost equation

$Q_{t} \quad$ turbine heat rate $\left[\frac{B t u}{k W h}\right]$

$Q_{\text {th }}$ overal1 heat rate $\left[\frac{B t u}{k W h}\right]$ 


\section{NOMENCLATURE (Continued)}

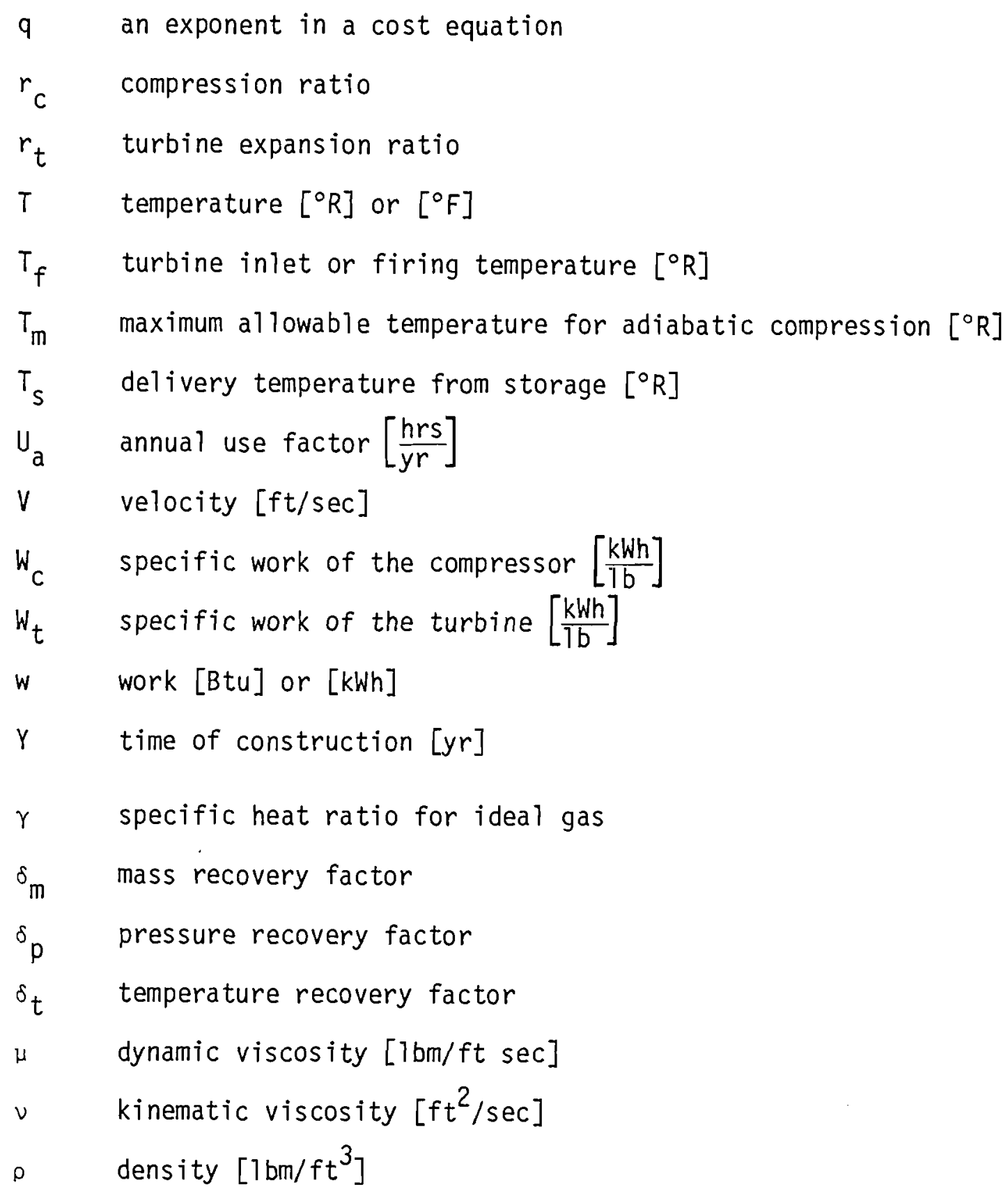




\section{OFFSITE}

No. of

Copies

A. A. Churm

ERDA Chicago Patent Group

Chicago Operations office

9800 South Cass Avenue

Argonne, IL 60439

27 ERDA Technical Information Center

G. C. Chang

Mechanical Energy Storage Branch

Division of Conservation Research and Technology

Energy Research and Development Administration

Washington, DC 20545

A. N. Heller

Assistant Administrator for Conservation

Energy Research and Development Administration

Washington, DC 20545

G. F. Pezdirtz

Mechanical Energy Storage Branch

Division of Conservation Research and Technology

Energy Research and Development Administration

Washington, DC 20545

N. F. Sather

Fossil Energy Programs

Argonne National Laboratory

9700 South Cass Avenue

Argonne, IL 60439

R. D. Vergara

Battelle Columbus Laboratories

505 King Avenue

Columbus, $\mathrm{OH} 43201$

J. Veigel

Cal ifornia Energy Commission

1111 Howe Avenue

Sacramento, CA 95825 


\section{DISTRIBUTION (Continued)}

\section{OFFSITE}

No. of

Copies

V. R. Cooper

Electric Power Research Institute

P. 0. Box 10412

Palo Alto, CA 94303

J. W. Pepper

Electric Power Research Institute

P. 0. Box 10412

Palo Alto, CA 94303

W. H. Day

Gas Turbine Division

Building 500

Schenectady, NY 12345

J. B. Bush

Advanced Energy Programs Operation

General Electric Company

P. 0. Box 43

Schenectady, NY 12301

W. S. Mitchell

Harza Engineering Company

150 South Wacker Drive

Chicago, IL 60606

T. Stephens

Lincoln Laboratory

Massachusetts Institute of Technology

244 Wood Street

Lexington, MA 02173

W. J. Lang

Strata Power Company

623 Dawes

Libertyville, IL 60048

R. D. Lessard

United Technologies Research Center

Silver Lane

East Hartford, CT 06108 


\section{DISTRIBUTION (Continued)}

\section{OFFSITE}

No. of

Copies

D. L. Katz

Department of Chemical Engineering

University of Michigan

2011 Washtenaw

Ann Arbor, MI 48104

D. L. Ayers

Fluid Systems Laboratory

Westinghouse Electric Corporation

1291 Cumberland Avenue

West Lafayette, IN 47906

R. J. Krang

Department of Mechanical Engineering

West Virginia University

Morgantown, WV 26506

ONSITE

ERDA Richland Operations Office

Research and Development Programs Division

P. G. Holsted

54 Battelle-Northwest

D. B. Cearlock

C. R. Cole

J. G. DeSteese

B. C. Fryer

A. J. Haverfield

W. S. Kelly

D. K. Kreid (32)

W. V. Loscutoff

W. R. McSpadden

D. E. Oleson

L. T. Pedersen

M. S. Quigley

D. L. Reid

D. H. Stewart

A. M. Sutey

D. S. Trent

J. W. Upton

M. Vagins

N. G. Wittenbrock

Technical Information (3)

Technical Publications 